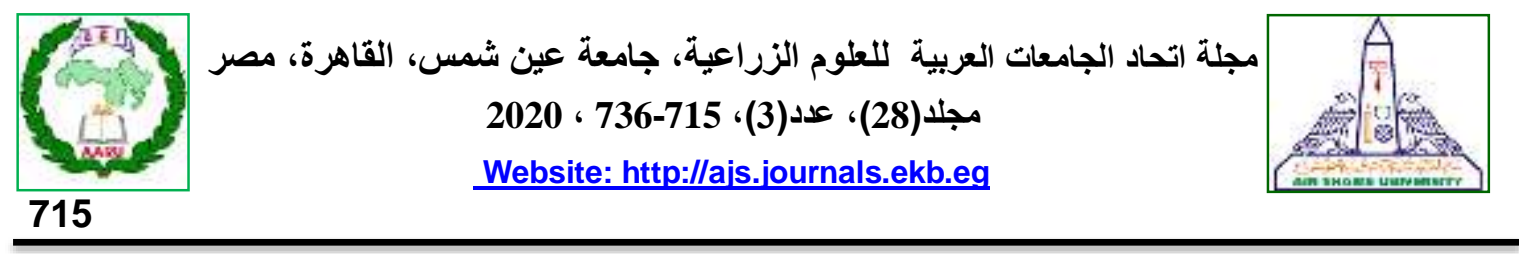

دراسة مقارنة لتنافسية أهم المحاصيل الثتوية باستخذام نموذج التقريب الخطى

[53]

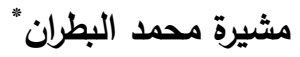 \\ قسم العلوم التجارية - المعهة العالى للدراسات النوعية - الجيزة - مصر مصدران
}

${ }^{*}$ Corresponding author: moshirabatran@hotmail.com

Received 19 July, 2020

Accepted 5 September, 2020

لتقدير مرونات استجابة العرض للمسـاحة ضــن نظام

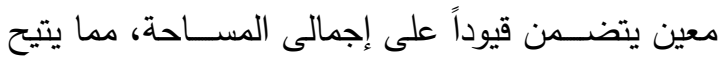
حسـاب مرونات غلة الحجم والتي تُعرف بأنها إسـتجابة التهابة

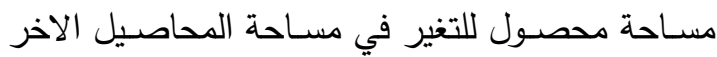

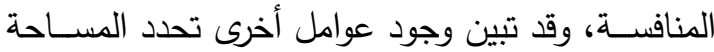

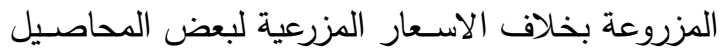

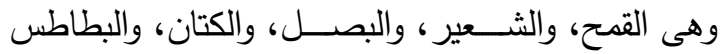

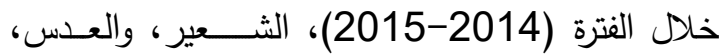

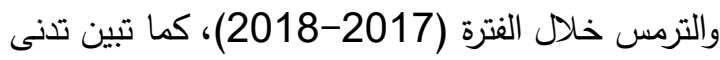

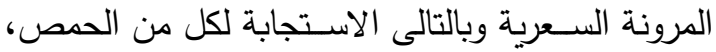

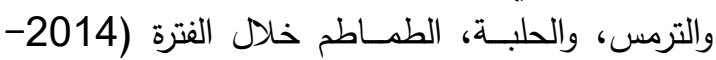

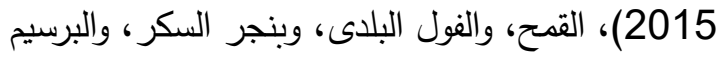

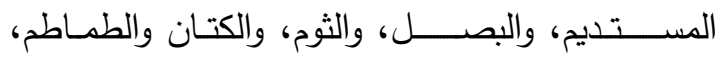

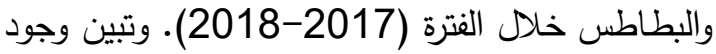

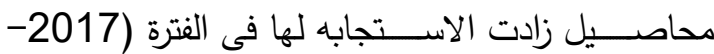

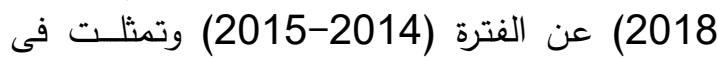

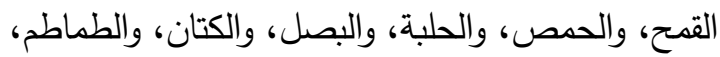

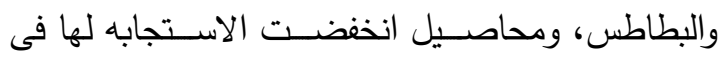
الفترة الثانية عن الاولى وتمثلت فى باقى المحاصـــيل،

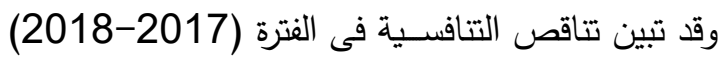
بصـفة عامة بالمقارنة بالفترة (2014-2015). وتبين الفين

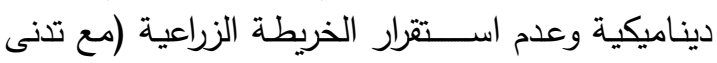
تأثر بعضها) رغم تقارب الفترات.

الكلمات المفتاحية: تنافسية، المحاصيل الشتوية، نموذج، التقريب الخطى، استجابة العرض، الخريطة

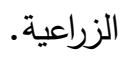

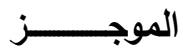

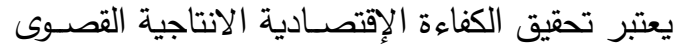

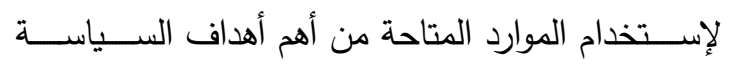

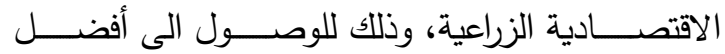

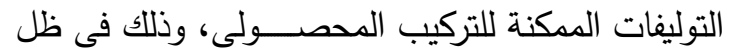
تتافســية المحاصـــيل على الارض الزراعية المحدودة

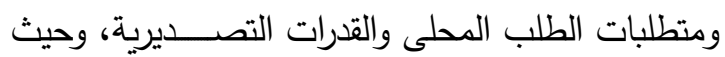

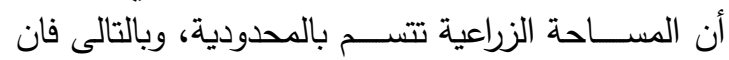

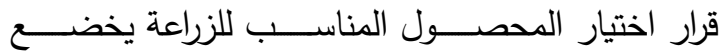

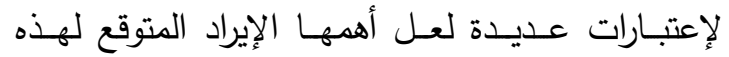
المحاصـيل، حيث أنه يعكس العديد من العوامل الهامة الإنة

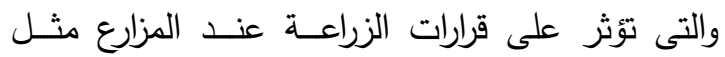

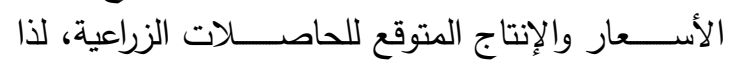

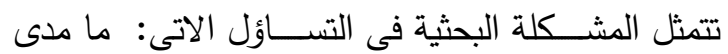

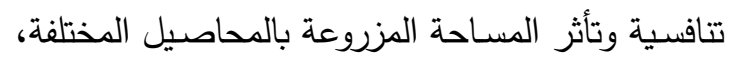

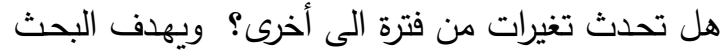

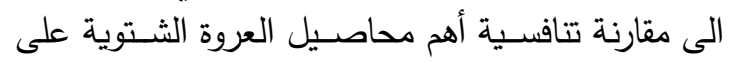
مســـاحـة الارض الزراعيـة خلال الفترتين (2017)

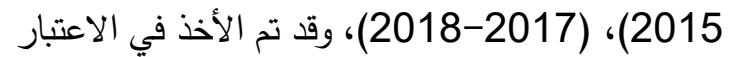
أن التنافس بين هذه المحاصيل على المساحة فى ضواء

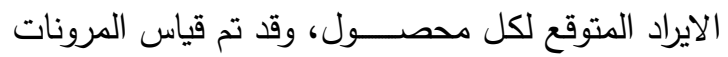

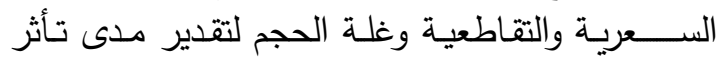

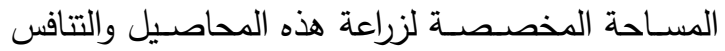

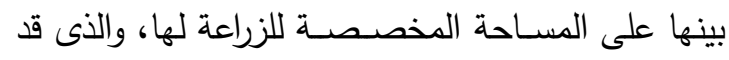
يثـير الى مدى تغير الخربطة الزراعية فى المســتقبل.

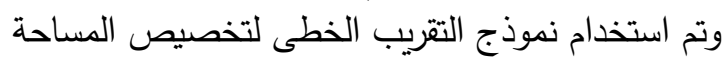




\section{الهذف البحثى}

يهدف البحث الى مقارنة تتافســية أهم محاصـــيل

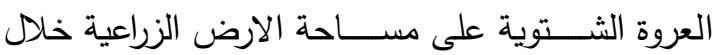

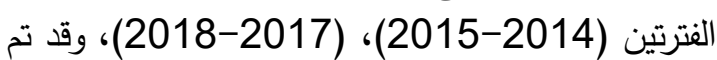
الأخذ في الاعتبار أن التتافس بين هذه المحاصيل على لى

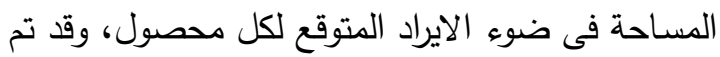
قياس المرونات السـعرية والتقاطعية وغلة الحجم لتقدير لتولير

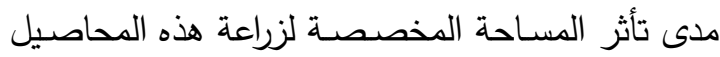

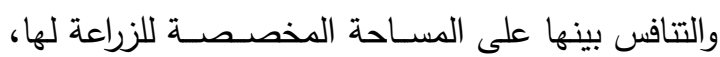

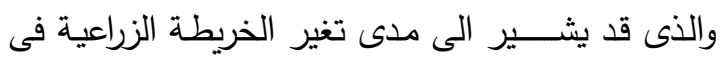

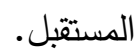

الطريقة البحثية ومصـــادر البيانات: تعتمد الطريقة

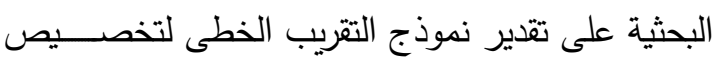

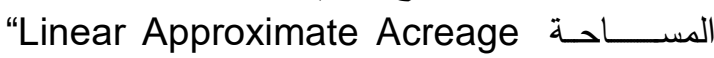
BB-) والذى يعتمد على نموذج Allocation Model" (BV مع إخخال بعض التعديلات عليه. وقد طور كل

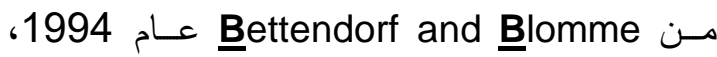
 قياسى لتقدير مرونات استجابة العرض للمساحة ضدن

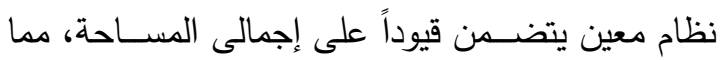

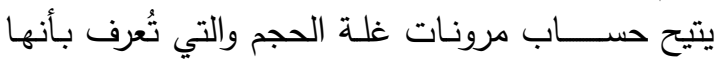

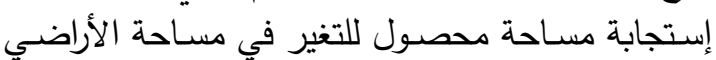
الزراعية(2، 3).

ويفترض النموذج المســـتخدم (BB-BV) أن قرار

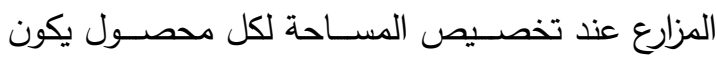

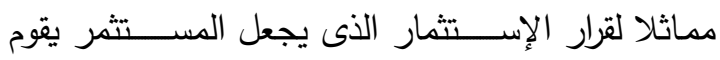
بتتويع محفظته الإستثمارية وذللك وفقا للأسعار النسبية، ومدى تفضيل المخاطرة، ومدى توافر الميزانية. وبالتالى لئى الإلى

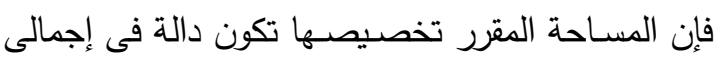

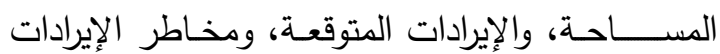

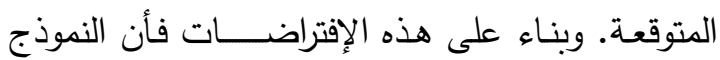

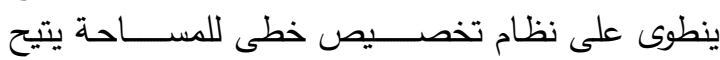

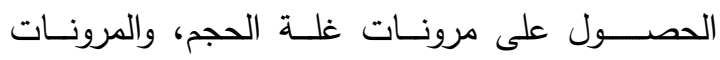
التقاطعية، وفى عام 1999 وضع لنق Holt صيغة لنموذج سـميت بنموذج التقريب الخطى لتخصيص (BB-BV)

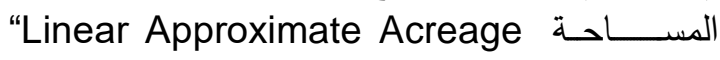
. ${ }^{(76)}$ Allocation Model”

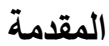

يعتبر تحقيق الكفاءة الإقتصـادية الانتاجية القصـوى القيا

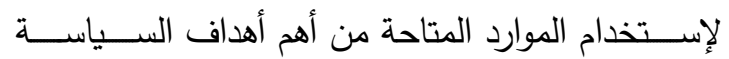

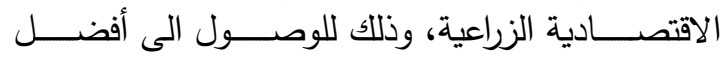

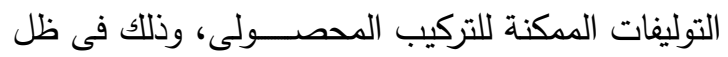

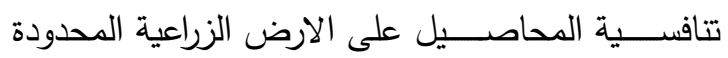

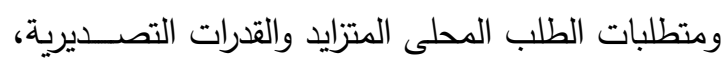
وتبلغ المسـاحة المحصــولية حوالى 15.69 15.

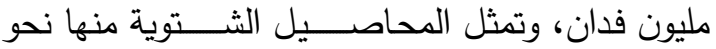

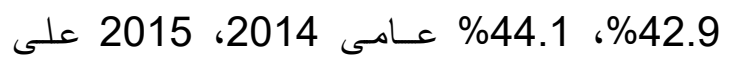

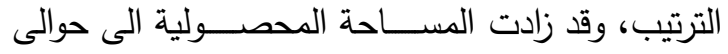

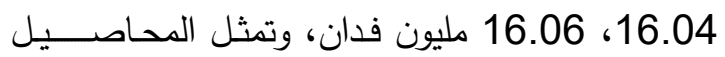

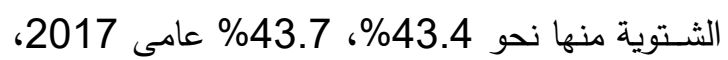
2018 على الترتيب- جدول 1 بالملحق.

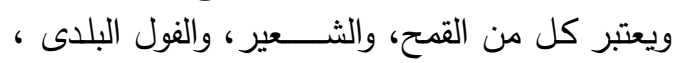

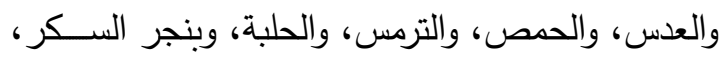

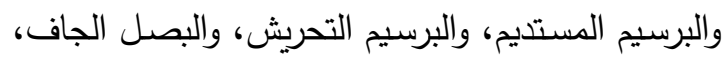

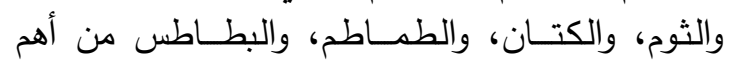

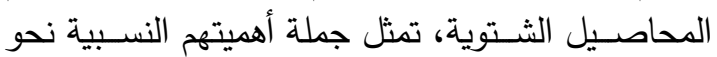
93.52\%، 93.28 من جملة المحاصـيل الشـتوية

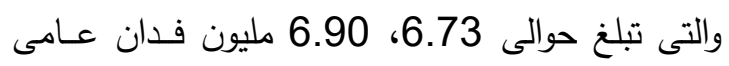
2014، 2015 على الترتيب، وتمثل جملـة أهميتهر النســبــة نحو 92.72\%، 93.26\% من جملــة المحاصـيل الثــتوية والتى تبلغ حوالى 92.72، 6.96، 7.02 مليون فـدان عـامى 2017، 2018 على الترتيـبـ جذول 1 بالملحق.

\section{المشكلة البحثية}

تتسـم المســاحة الزراعية بالمحدودية ويتنافس عليها العديد من المحاصـيل في كل موســ، وبالتالى فان قرار

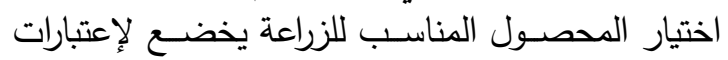

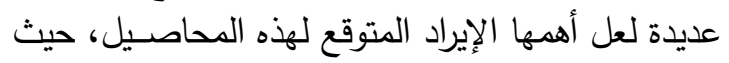

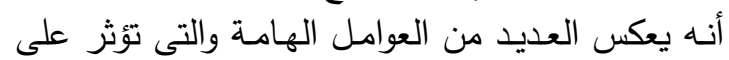

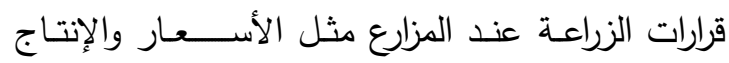

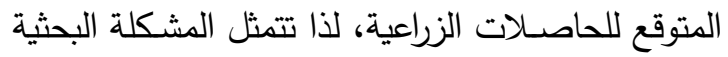

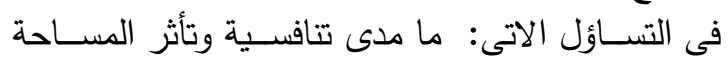

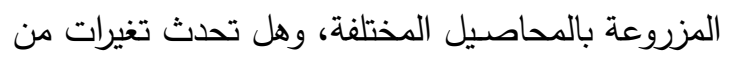

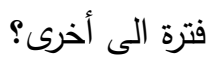


$\mathrm{a}=\mathrm{b} a_{\text {tot }}+\mathrm{S}^{*} \mathrm{r}^{\mathrm{e}}$

وللحصـول على نموذج خطى لتخصيص المسـاحة

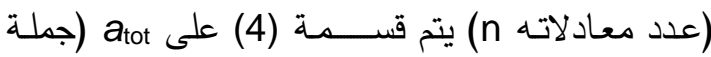

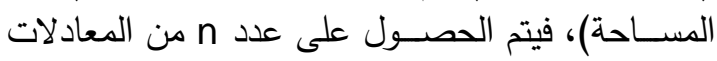

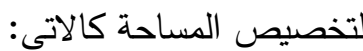

$\mathrm{V}=\mathrm{b}+\mathrm{Sr}^{\mathrm{e}}$

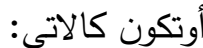

$\mathrm{V}_{\mathrm{i}}=\mathrm{b}_{\mathrm{i}}+\sum_{\mathrm{j}} \mathrm{S}_{\mathrm{ij}} \mathrm{r}^{\mathrm{e}} \mathrm{j}, \quad \mathrm{i}=1, \ldots, \mathrm{n}$

$$
\mathrm{S}=\mathrm{S} / a_{\text {tot }}, \mathrm{V}_{\mathrm{i}}=\mathrm{a} / a_{\mathrm{tot}}
$$

ويعتبر النموذج (المعادلة 5، 6) نموذج تخصسيص

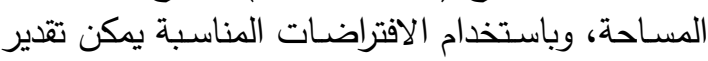

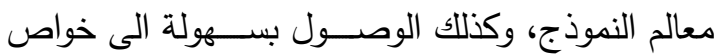

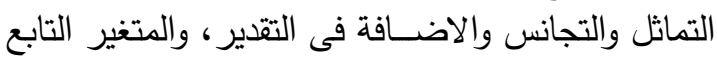

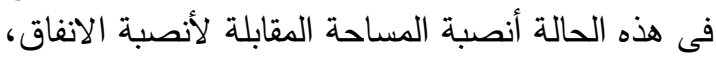

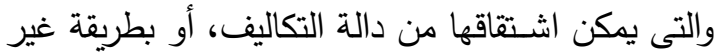

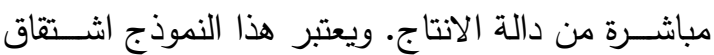
ممهد لنموذج BB - BV وذلك للبيانات المقطعية أو

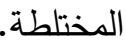
ويمكن الحصول على المرونات من الصيغ التالية:

المرونة السعرية والتقاطعية - (المية

$$
\varepsilon_{i j}=\frac{\partial a_{i}}{\partial p_{j}^{e}} \frac{P_{j}^{e}}{a_{i}}=\frac{S_{i j}}{V_{i}} p_{j}^{e} y_{j}^{e}, \quad \forall i, j
$$

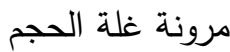

$$
\eta_{i}=\frac{\partial a_{i}}{\partial a_{t o t}} \frac{a_{t o t}}{a_{i}}=\frac{b_{i}}{V_{i}}, \quad i=1, \ldots, n
$$

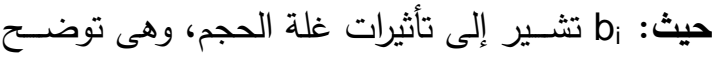

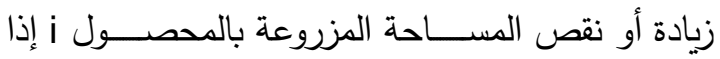

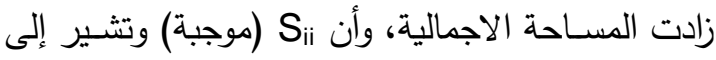

اشتقاق النموذج المستخدم(4، 5، 8):

يعتمد نموذج التقريب الخطى لتخصـيص المسـاحة "Linear Approximate Acreage Allocation (BB-BV) مع بعض نموذج التعديلات، ويفترض هذا النموذج أن المزارع عندما يأخذ القرارات

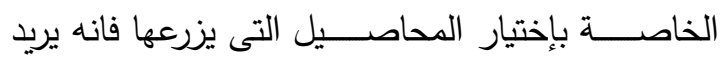

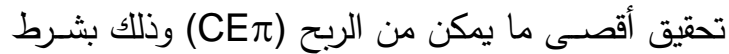

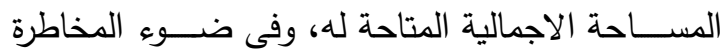

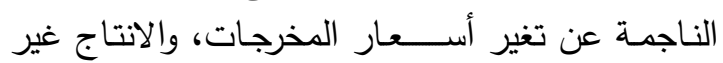

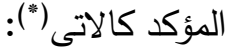

$\operatorname{Max}: \mathrm{CE}(\pi)=\left\{\mathrm{a}^{\prime} \mathrm{r}^{\mathrm{e}}-1 / 2 \lambda^{\prime} \sum \mathrm{a} \mid a_{t o t}-\mathrm{i}^{\prime} \mathrm{a}\right\}$

حيث: a عبارة عن n متجه من المسـاحة المخصسصـة

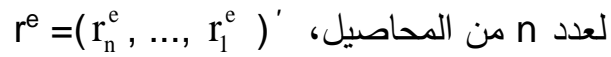
عبارة عن n متجه الايراد المتوقع، وتشير $\lambda$ الى معامل

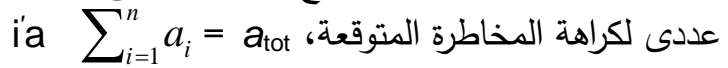

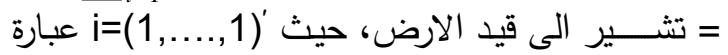

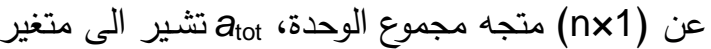

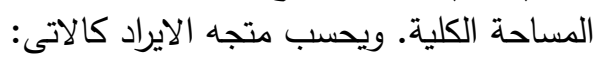
$r_{i}^{e}=E\left(p_{i} y_{i}\right)=p_{i}^{e} y_{i}^{e}+\operatorname{cov}\left(p_{i}, y_{i}\right)$

حيث: E تشير الى التوقع، pe تشير الى سـر الوحدة

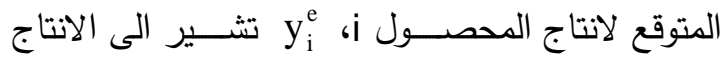
المتوقع من وحدة المساحة للمحصول أ، (") تثير الى التغاير بين السعر والانتاج،

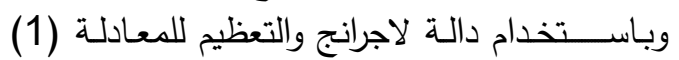

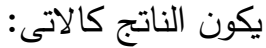
$\max \mathrm{L}(\mathrm{a}, \mu)=\mathrm{a}^{\prime} \mathrm{r}^{\mathrm{e}}-1 / 2 \lambda \mathrm{a}^{\prime} \Sigma \mathrm{a}-\mu\left[a_{\text {tot }}-\mathrm{i}^{\prime} \mathrm{a}\right]$

حيث: ب تتنمى إلى R وهى عبارة عن مقياس عددى

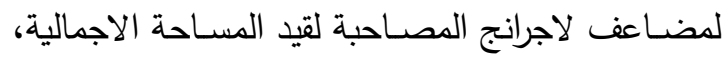
ويكون متجه التخصيص الامثل للمساحة كالاتى:

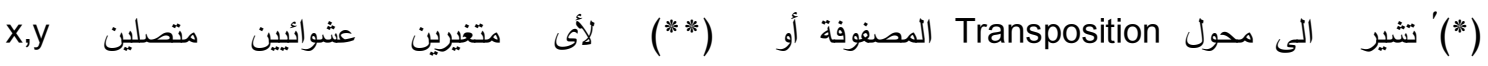
فان: 


$$
\begin{aligned}
& \mathrm{S}_{\mathrm{ij}}=\mathrm{S}_{\mathrm{ji}} \text { for } \mathrm{i} \neq \mathrm{j} \text { : قيد التماثل: } \\
& \text { صحة النموذج: }
\end{aligned}
$$

وقــــــ تم الاعتمـاد على بيـانــات وزارة الزراعــة

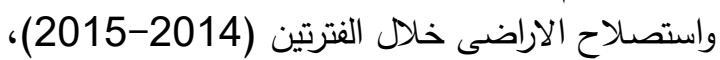

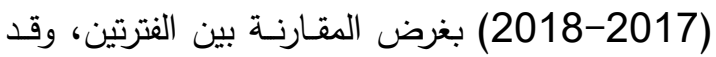
اسـتبعاد عام 2016 بغرض فصــل التاثير الممتد بين الفين

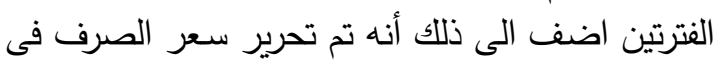
نوفمبر 2016.

\section{النتائج}

يتضـــح من الجدول 2، 3 بالملحق معنوية النموذج

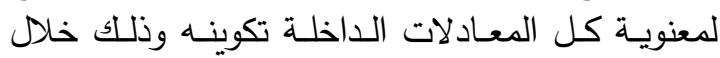

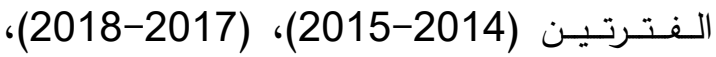

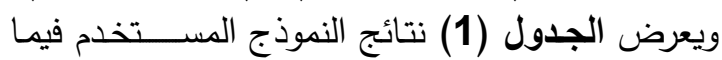
يتعلق بمرونات المحاصيل موضـع الدراسـة خلال الفترة

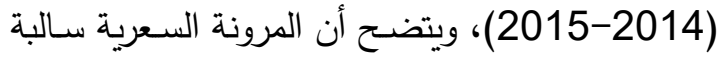

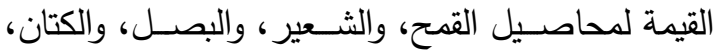

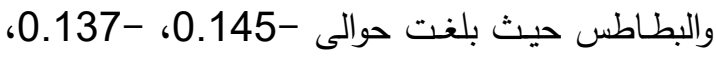

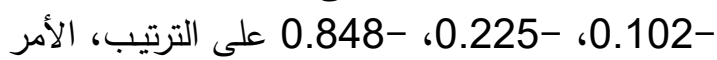

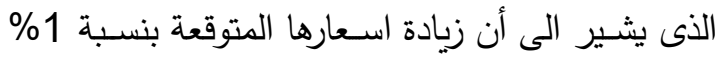

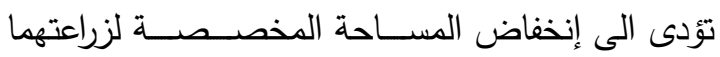

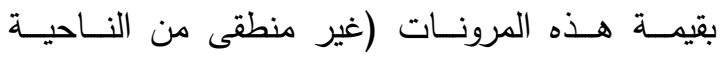

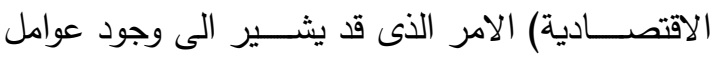

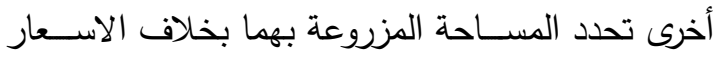

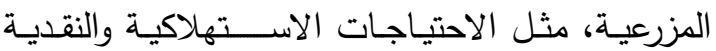

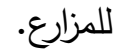

زيادة الايراد المتوقع للمحصــــا i التى تؤدى إلى زيادة المساحة المزروعة بالمحصول، وأن Sij سالبة (موجبة)

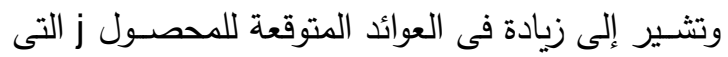

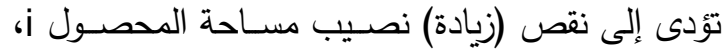

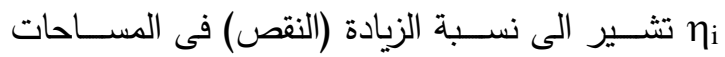

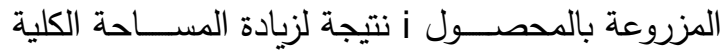
بحوالى 1\% ع تشير إلى مرونات استجابة المساحة السعرية والتقاطعية. النموذج المستخدم $\mathrm{V}_{\mathrm{ijt}}=\mathrm{b}_{\mathrm{i}}+\sum_{\mathrm{i}=1}^{\mathrm{n}} \sum_{\mathrm{j}=1}^{\mathrm{m}} \mathrm{s}_{\mathrm{ij}} \mathrm{r}_{\mathrm{ijt}}^{\mathrm{e}}+\sum_{\mathrm{j}=1}^{\mathrm{m}} \mathrm{c}_{\mathrm{j}} \mathrm{D}_{\mathrm{jt}}+\mathrm{u}_{\mathrm{ijt}}$

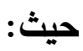
تثـير إلى نسـبة مسـاحة المحصــول الى إجمالى ل المساحة. تشير إلى الايراد المتوقع للمحصول. re

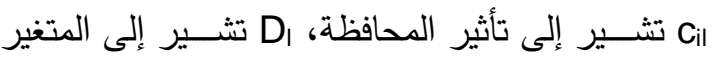
الصورى الخاص بالمحافظات. n تشير الى عدد المحاصيل (15 محصول شتوى).

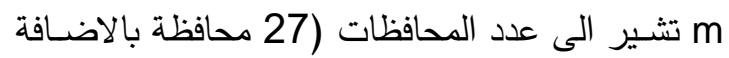
الى النوبارية)، unijt الخطأ العشوائى. مع الاخذ فى الاعتبار القيود التالية

$$
\begin{aligned}
& \sum_{i=1}^{n} b_{i}=1, \sum_{i=1}^{n} s_{i}=0 \text { and : قيد الإضافة: } \\
& \sum_{j=1}^{m} c_{j}=0 \\
& \text { - } \sum_{j=1}^{m} s_{j}=0 \quad \text { : }
\end{aligned}
$$




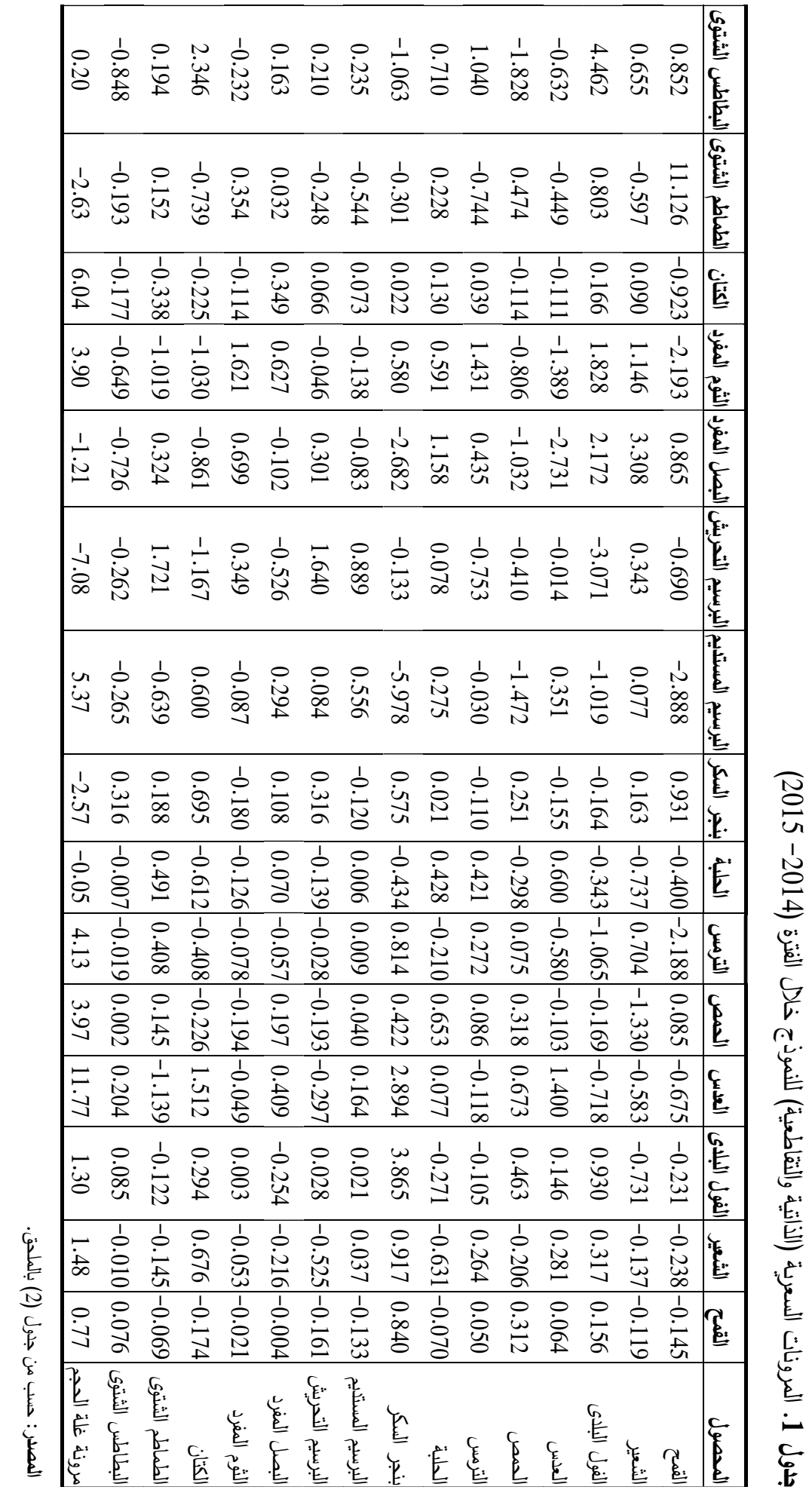




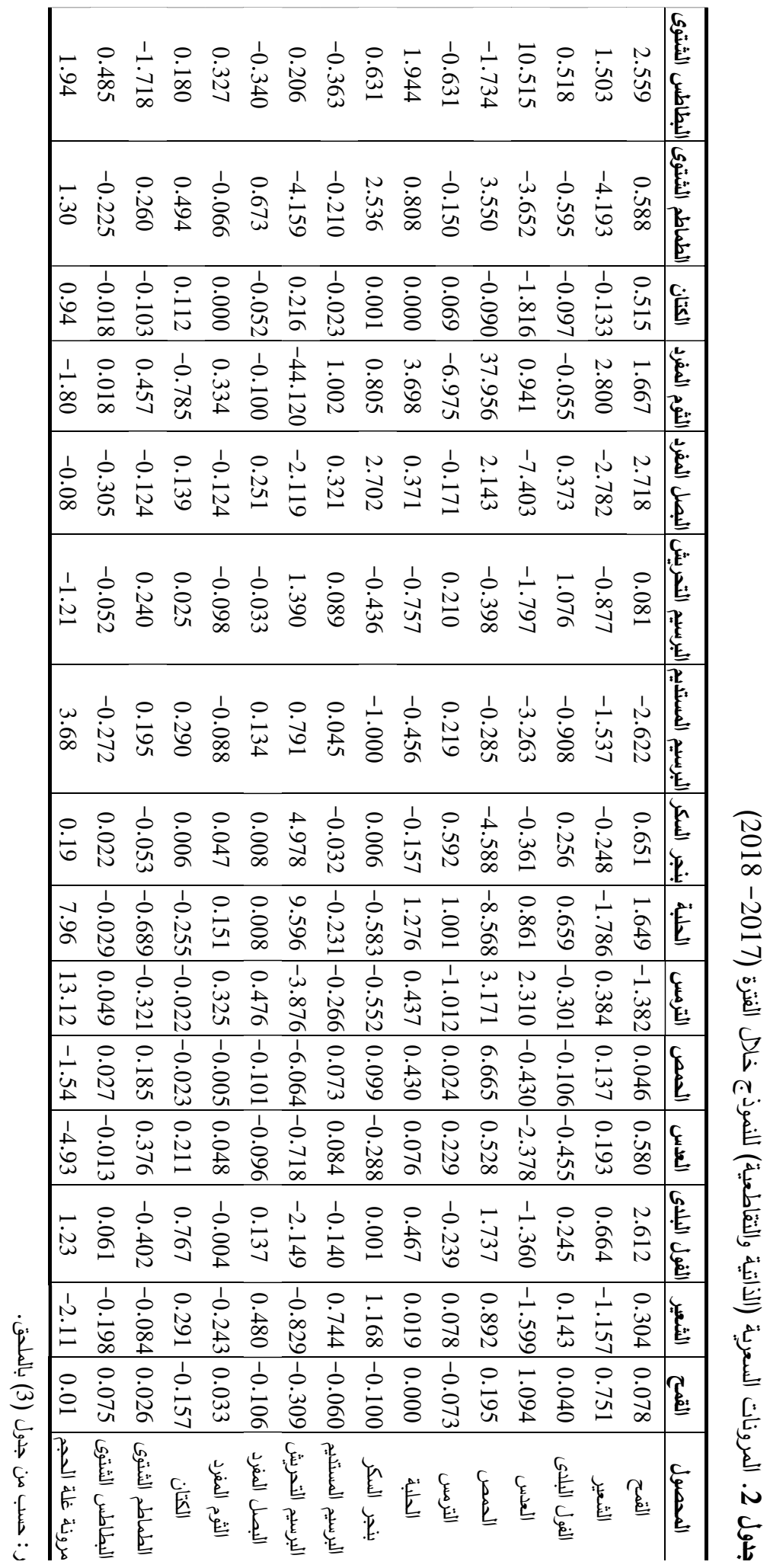




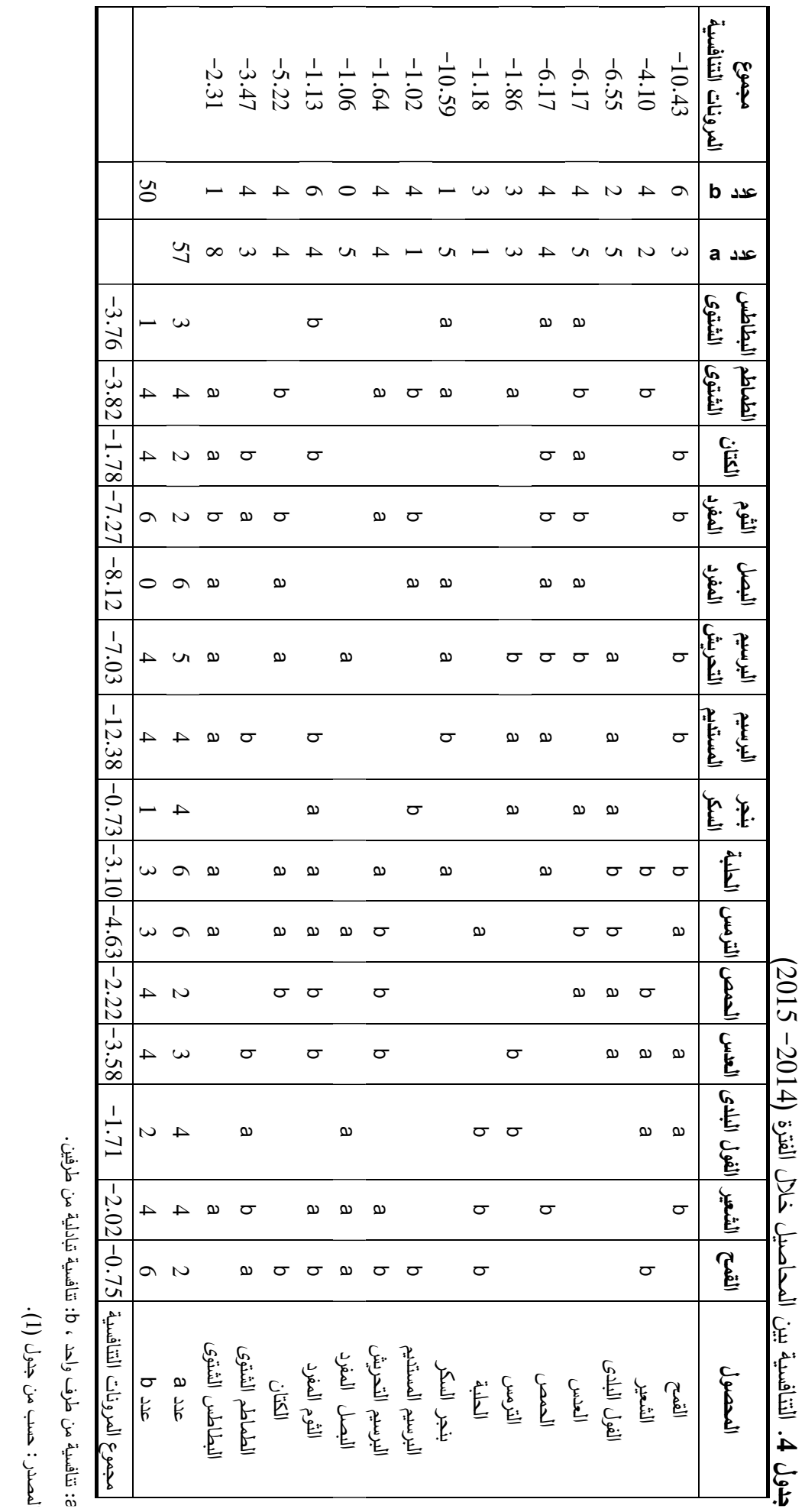

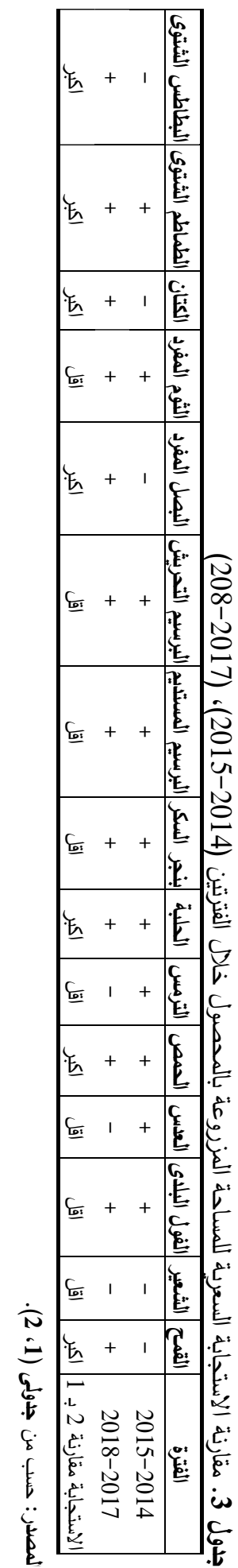




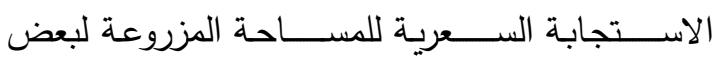
المحاصيل بالمقارنة باستجابة باقى المحاصيل.

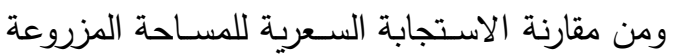

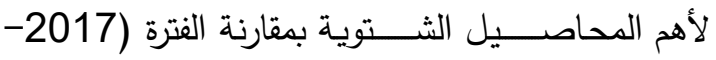

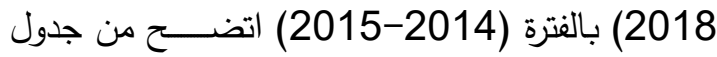
(3) انه يمكن تقسـم المحاصـيل الى قسـمين محاصسيل زادت الاستجابه لها فى الفترة الثانية عن الاولى وتمثلت

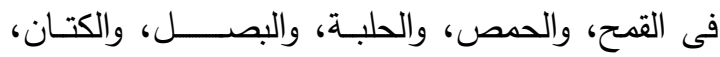

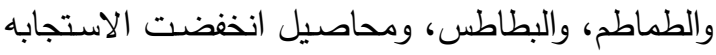

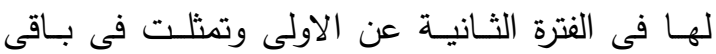

\section{ويتضــــح من الجــدولين 1، 1، 4 ومن المرونــة}

التقاطعية(") ووفقا لمجموع المرونات التتافسية (السـالبة)

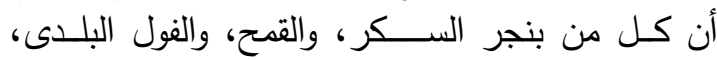

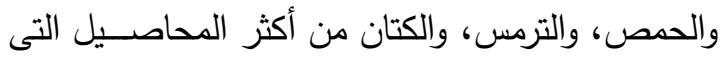

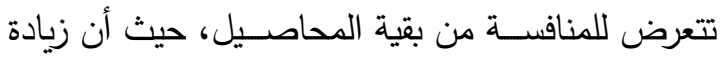

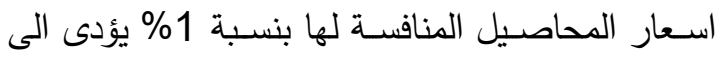

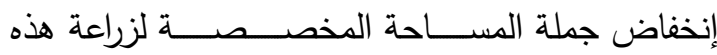

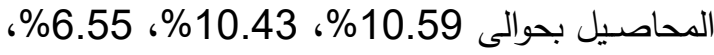

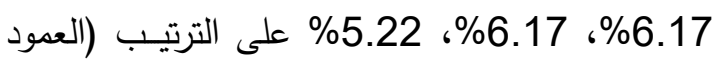
الاخير جدول 4). فى حين كانت محاصــيل البرســيم المسـتديم، والبصـل، والبرسيم التحريش، والثوم من أكثر المحاصيل المنافسة حيث أن زيادة اسعارها بنسبة 1 1

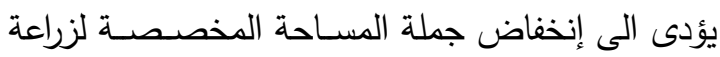

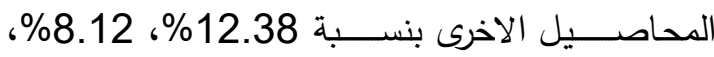

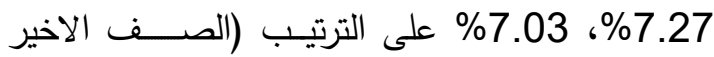
جدول 4)، وذلك خلال الفترة (2014-2015). ويتضح من الجدولين 2، 5 ومن المرونة التقاطعية

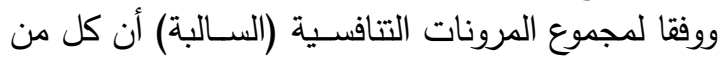

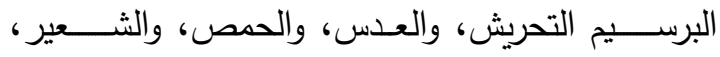

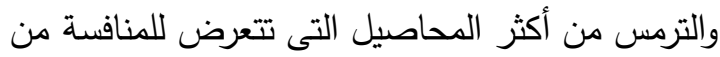

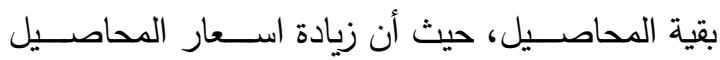

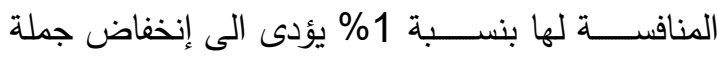

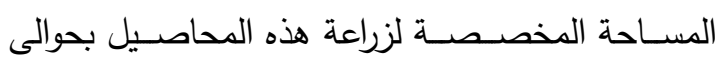
×11.56 \% \%64.34 8.24 على الترتيب، (العدود الاخير جدول 5). فى \%
كما يتضـــــح أن المرونـة الســـعريـة موجبـة لبقيـة

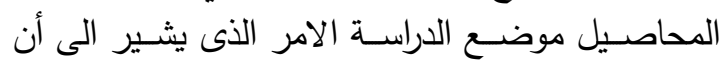

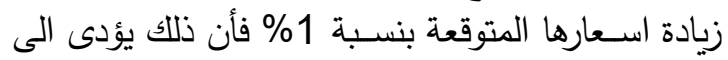

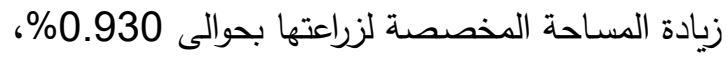

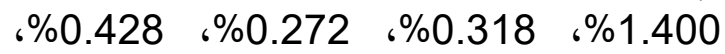

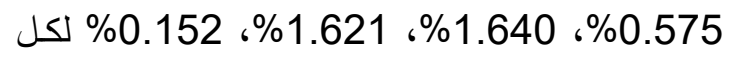

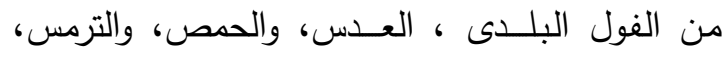

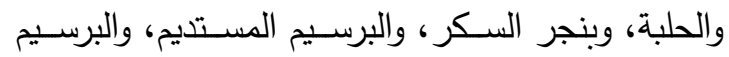
التحريش، والثوم، والطماطم على الترتيب. مع ملاحظة ولنة

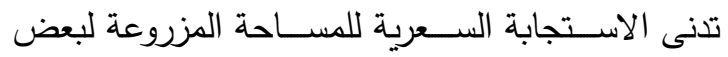
المحاصيل بالمقارنة باستجابة باقى المحاصيل.

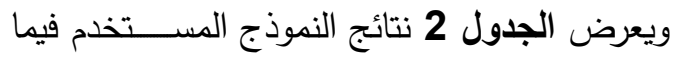
يتعلق بمرونات المحاصسيل موضـع الدراسـة خلال الفترة (2018-2017)، ويتضـح أن المرونـة السعريـة سـالبة القيمة لمحاصيل الشعير ، والعدس، والترمس حيث بلغت ولت الترون

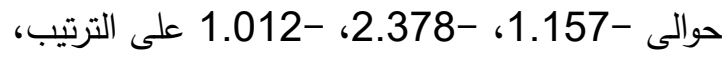

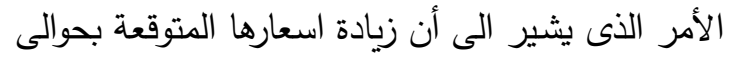

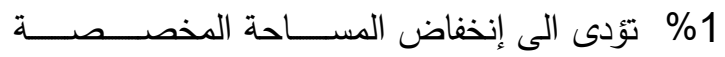
لزراعتهما بقيمة هذه المرونات (غير منطقى من الناحية

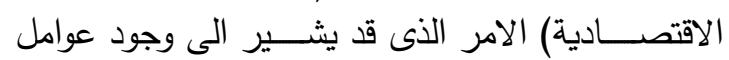

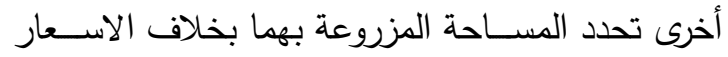

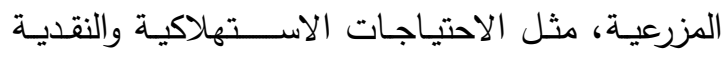
للمزارع. كمـا يتضـــــح أن المرونـة الســــريـة موجبـة لبقيـة

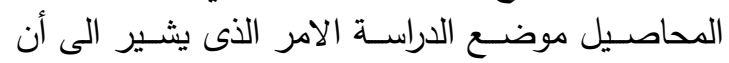

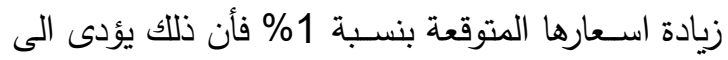

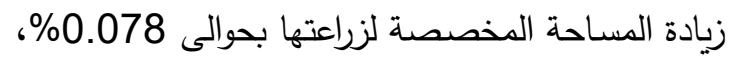

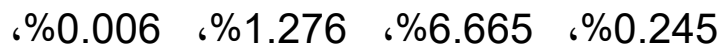
\% \%.112\% 0.0455

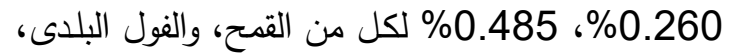

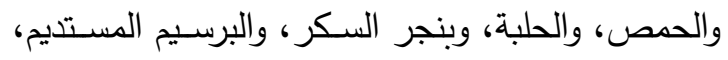

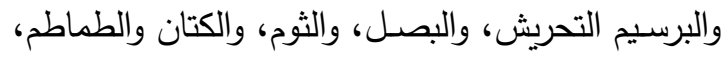

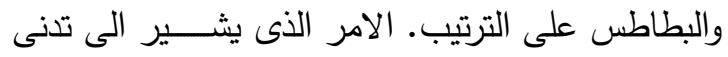

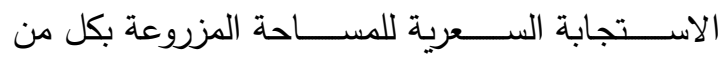

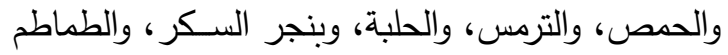
بالمقارنة باستجابة باقى المحاصيل، مع ملاحظة تدنى الطي 
ووفقا لعدد المحاصيل المتنافسة للفترة (2017-

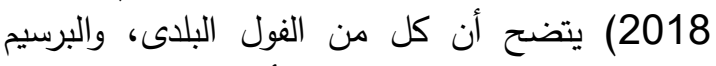
المستديم، والبرسيم التحريش من أكثر المحاصيل التى من التي

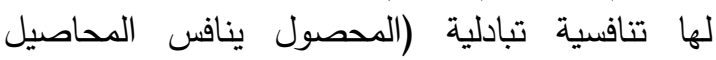

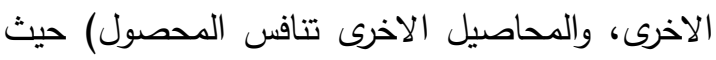

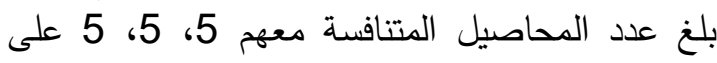

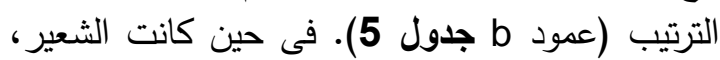

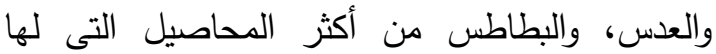

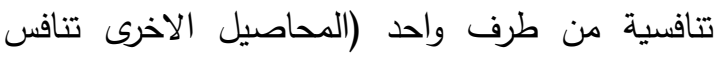

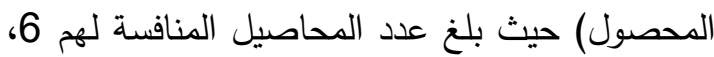

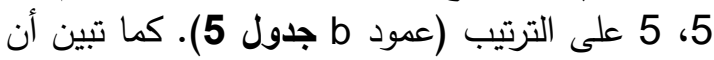

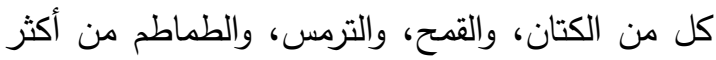
المحاصيل التى تنافس من طن طرف والترب، واحد (المحصول

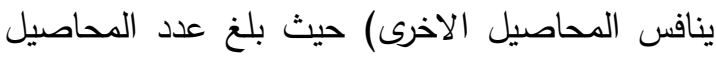

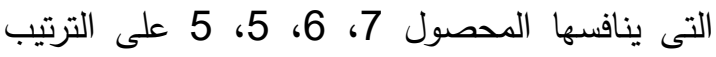
(صف a جدول 5).

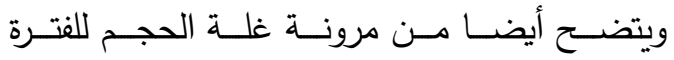

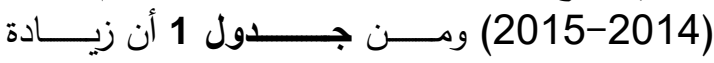

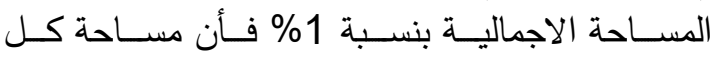

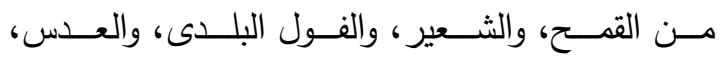

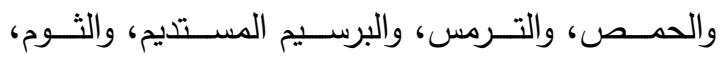

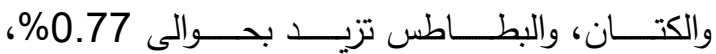

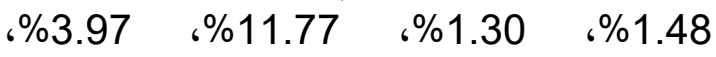

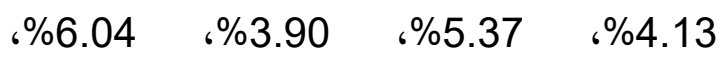

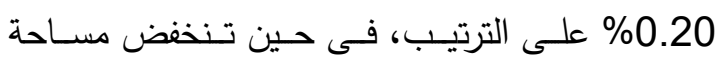

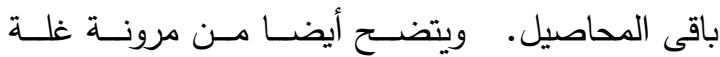

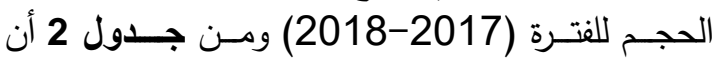

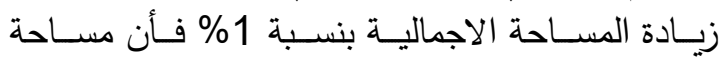

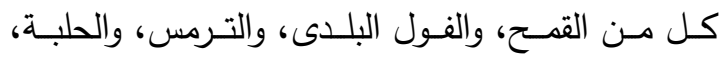

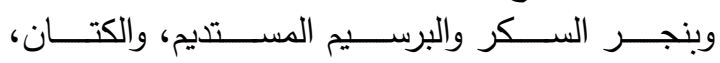

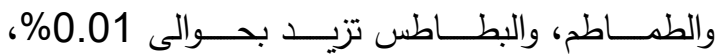

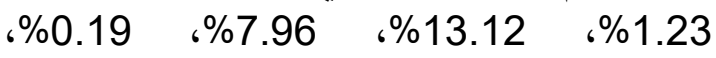

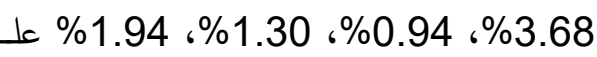

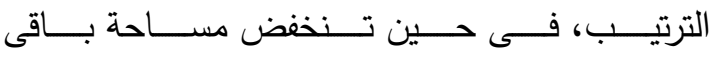

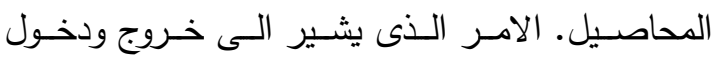

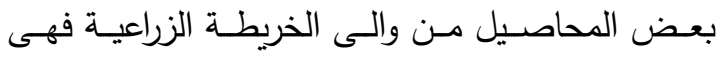

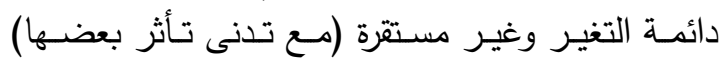
رغم تقارب الفترات - جدول (7).

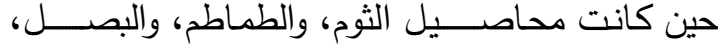

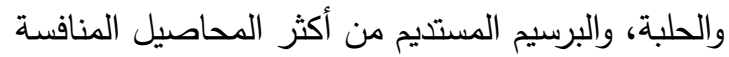

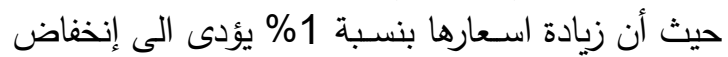

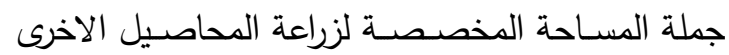

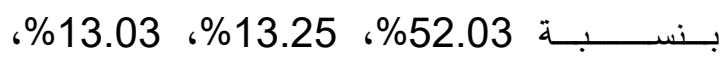
12.14\%، 10.43\% على الترتيب (الصــف الاخير جدول 5)، وذللك خلال الفترة (2017-2018). ومن مقارنة التنافسية لأهم المحاصيل الشتوية للفترة

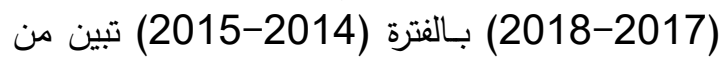

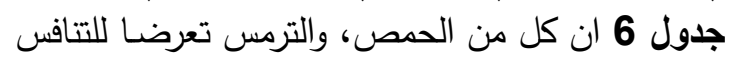

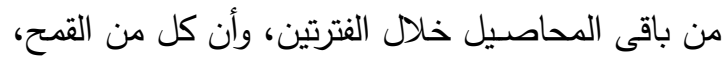

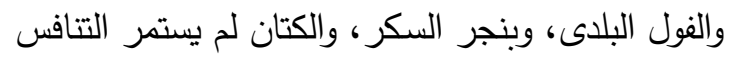

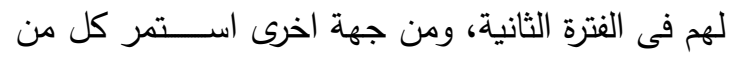

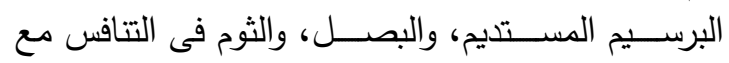

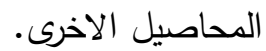
ويتضح من جدولى 4، 5 وجود 57 عملية تتافسية من جهة واحدة فى الفترة (2014-2017-2015) مقابل 54 وجن 54 فى الفترة (2017-2018)، ووجود 50 عملية تتافسية متبادلة فى الفترة (2014-2015) (2017) مقابل 45 فى الفترة (2017-2018)، مما يشير الى تتاقص التنافسية فى ملى الفيل الفترة الثانية بالمقارنة بالفترة الاولى. لئل

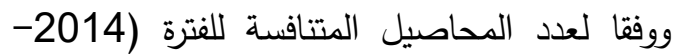

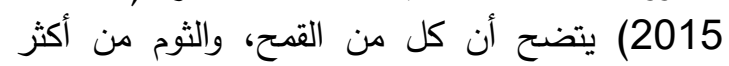

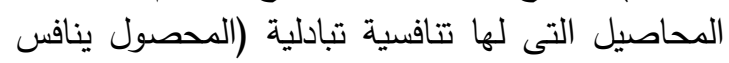

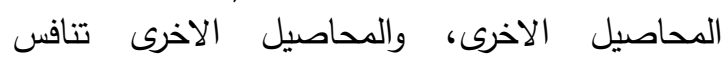
المحصول) حيث بلغ عدد المحاصيل المتنافسة معهم 6، المحيل

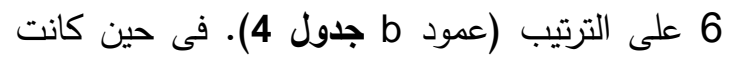

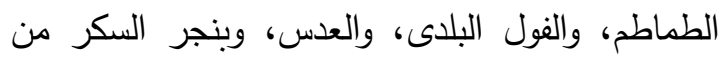

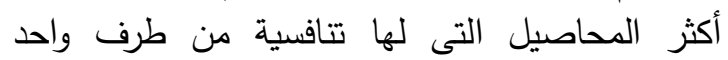

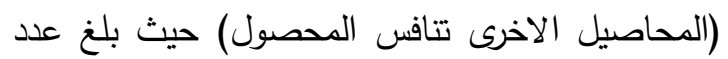

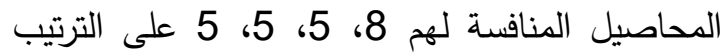
(عمود b جدول 4). كما تبين أن كل من الترمس، كل

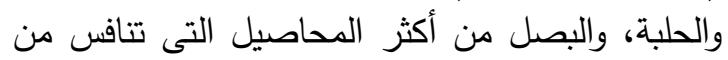
طرف واحد (المحصول ينافس المحاصيل الاخرى) حيث ليثل

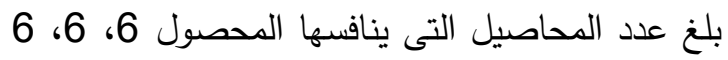
على الترتيب (صف a جدول 4). 


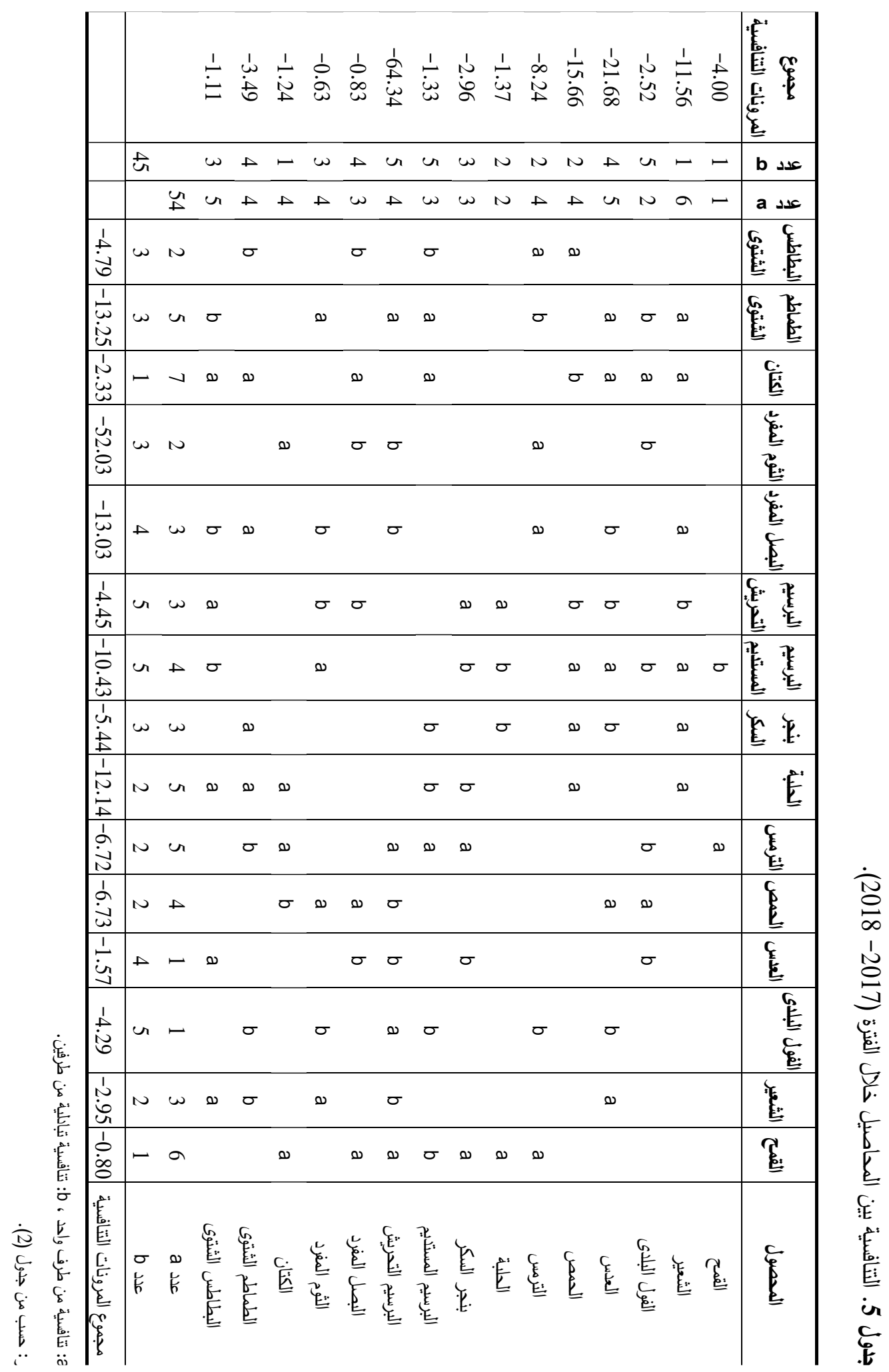


دراسة مقارنة لتنافسية أهم المحاصيل الثتوية باستخدام نموذج التقريب الخطى

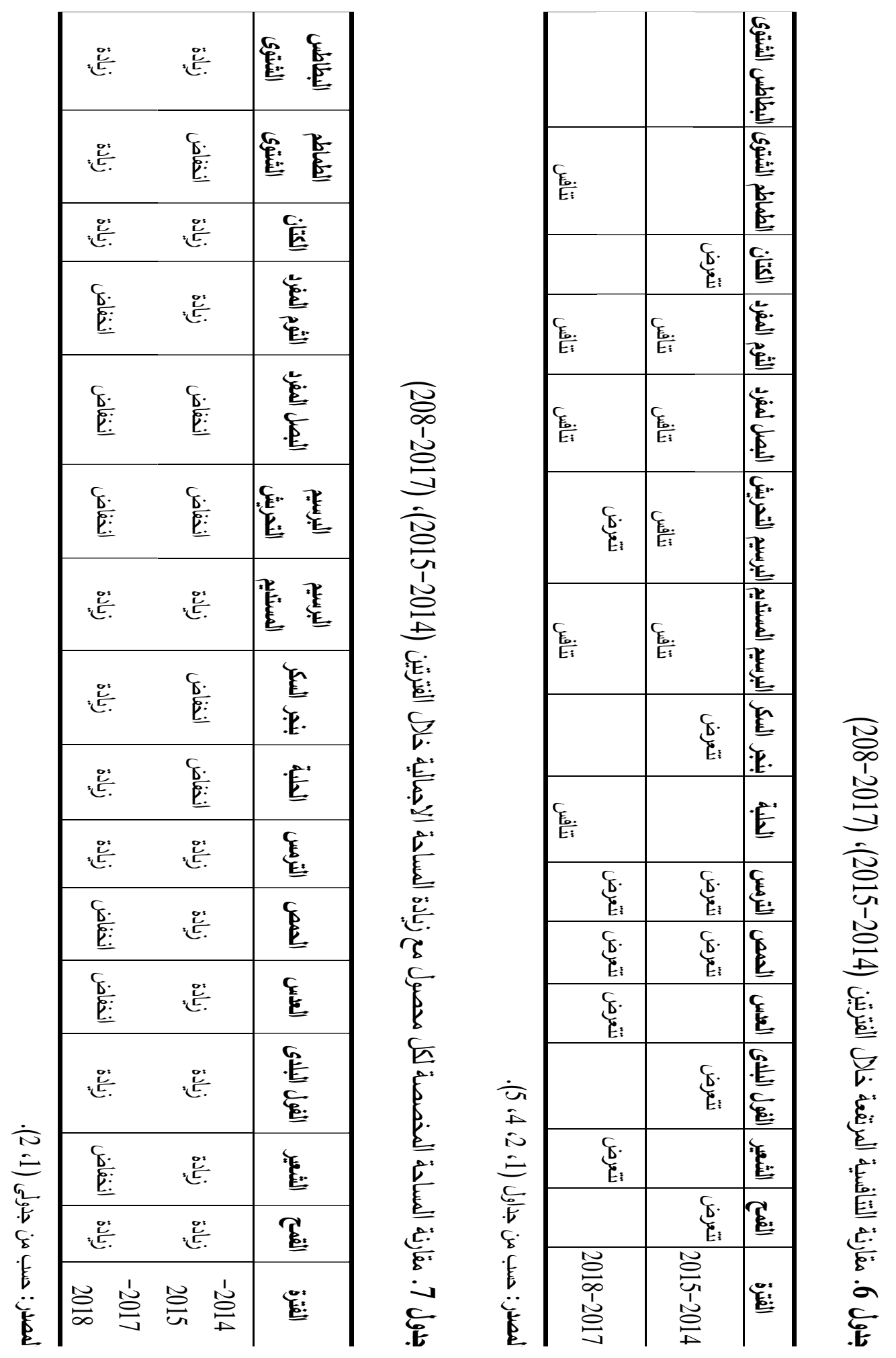


Bettendorf L. and Blomme J. (1994). An Empirical Study of the Distribution of Crops in Agricultural Land in Belgium: 1900-1939, Historical Social Res., 19, 53-63.

Bewley R., Young T. and Coleman D. (1987). A Systems Approach to Modeling Supply Equations in Agriculture, J. Agr. Econ., 38, 151166.

Choi J.S. and Helmberger P.G. (1993). Acreage Response, Expected Price Functions, and Endogenous Price Expectations, J. Agr. and Resource Econ., 18, 37-46.

Holt M.T. and Johnson S.R. (1989). Bounded Price Variation and Rational Expectations in an Endogeneous Switching Model of the U.S. Corn Market, Rev. Econ. and Statis, 71, 605-613.

Holt T. (1999). A Linear Approximate Acreage Allocation Model, J. of Agric. and Resource Economics, 24, 383397.

Koç A. Ali (2008). Acreage Allocation Model Estimation and Policy Evaluations for Major Crops in Turkey, Center for Agricultural and Rural Development, lowa State Univ., Working Paper 99-220.

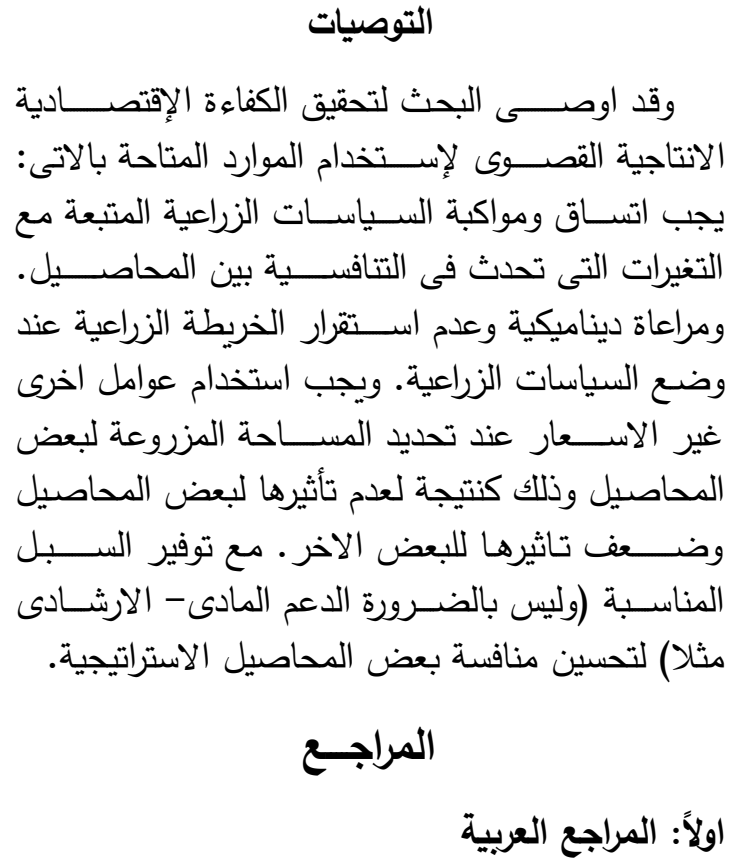

Barten A.P. and Vanloot C. (1996). Price Dynamics in Agriculture: An Exercise in Historical Econometrics, Econ. Modelling, 13, 315-331. 


\section{الملاحـق}

جدول 1. مساحة أهم المحاصيل الشتوية خلال الفترة (2014- 2018).

\begin{tabular}{|c|c|c|c|c|c|c|c|c|}
\hline$\%$ & 2018/2017 & $\%$ & $2017 / 2016$ & $\%$ & $2015 / 2014$ & $\%$ & $2014 / 2013$ & المحصول \\
\hline 24.030 & 1686242 & 25.944 & 1806116 & 18.823 & 1297898 & 19.463 & 1309312 & البرسيم المستديم \\
\hline 2.338 & 164037 & 2.995 & 208509 & 3.308 & 228061 & 3.304 & 222274 & البرسيم التحريش \\
\hline 45.001 & 3157765 & 42.201 & 2937865 & 50.408 & 3475669 & 50.740 & 3413424 & حـ \\
\hline 3.901 & 273738 & 3.022 & 210358 & 1.361 & 93866 & 2.138 & 143844 & الثــعير \\
\hline 1.267 & 88884 & 1.812 & 126152 & 1.270 & 87581 & 1.434 & 96444 & الفول البلدى \\
\hline 0.022 & 1561 & 0.036 & 2510 & 0.021 & 1457 & 0.014 & 975 & لمس لمس \\
\hline 0.041 & 2910 & 0.047 & 3269 & 0.068 & 4658 & 0.081 & 5432 & بـــــ \\
\hline 0.084 & 5920 & 0.065 & 4522 & 0.018 & 1267 & 0.022 & 1483 & كــــ \\
\hline 0.004 & 251 & 0.003 & 186 & 0.012 & 794 & 0.019 & 1299 & الترمـــس \\
\hline 0.192 & 13438 & 0.207 & 14407 & 0.108 & 7445 & 0.102 & 6887 & الكتـــــان \\
\hline 2.710 & 190139 & 2.680 & 186588 & 2.747 & 189396 & 2.387 & 160594 & البصــــلـ \\
\hline 0.577 & 40470 & 0.445 & 30993 & 0.435 & 29961 & 0.389 & 26183 & الثــــوم \\
\hline 7.022 & 492708 & 7.518 & 523382 & 8.048 & 554941 & 7.496 & 504299 & بنجر السكر \\
\hline 3.634 & 254971 & 3.316 & 230843 & 3.939 & 271574 & 3.025 & 203512 & البطاطس \\
\hline 2.438 & 171107 & 2.426 & 168878 & 2.714 & 187135 & 2.906 & 195500 & الطمــاطم \\
\hline 100.0 & 7017109 & 100.0 & 6961525 & 100.0 & 6895131 & 100.0 & 6727238 & الشتوية العروة \\
\hline 43.7 & 16.06 & 43.4 & 16.04 & 44.1 & 15.64 & 42.9 & 15.69 & المحمالي المساحة \\
\hline
\end{tabular}

* نسبة العروة الثتوية الى إجمالي المساحة المحصولية. المصدر: وزارة الزراعة واستصلاح الاراضى، الادارة المركزية للاقتصاد الزراعى، نشرة الاحصاءات الزراعية، أعداد مختلفة. 


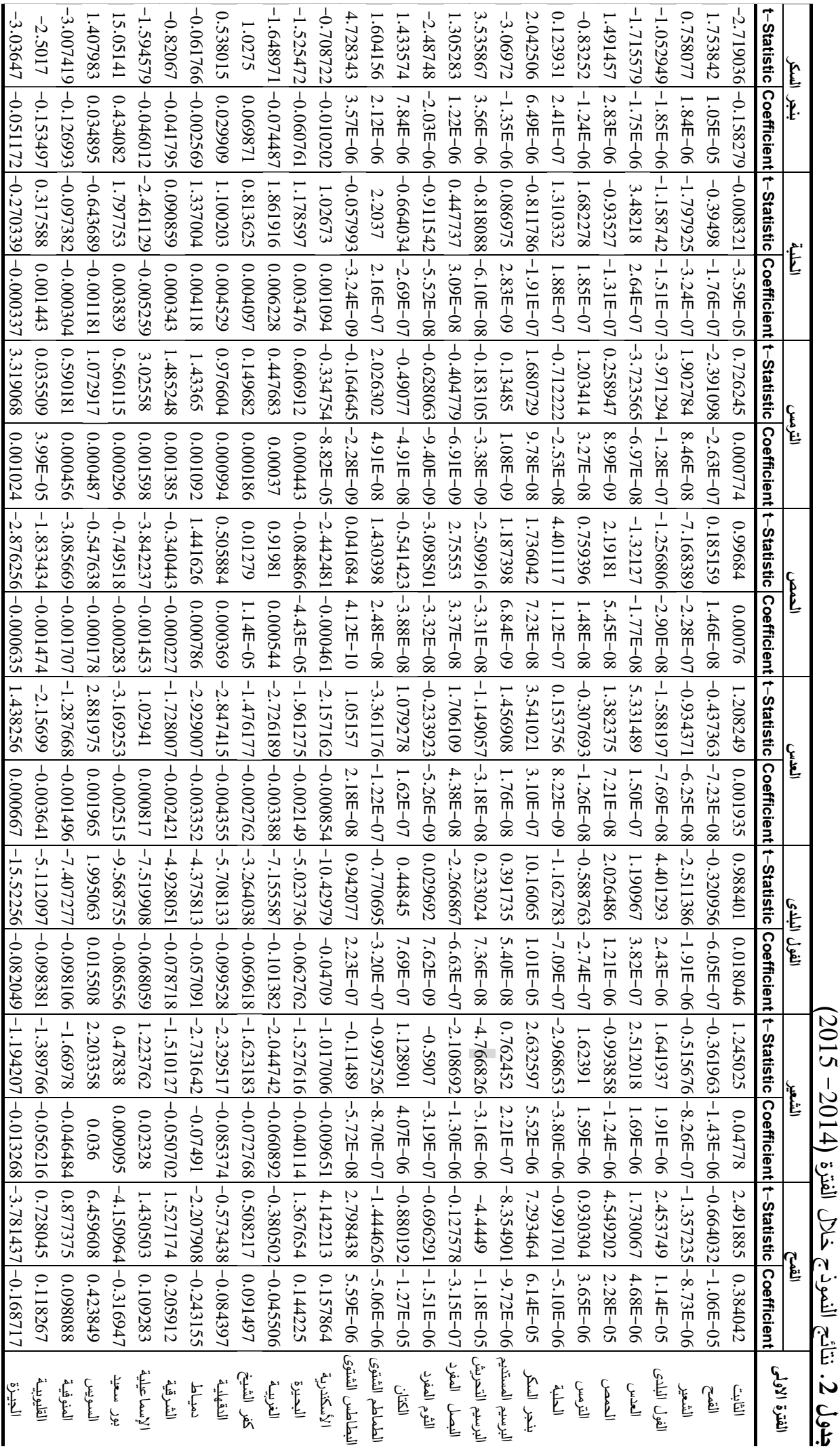




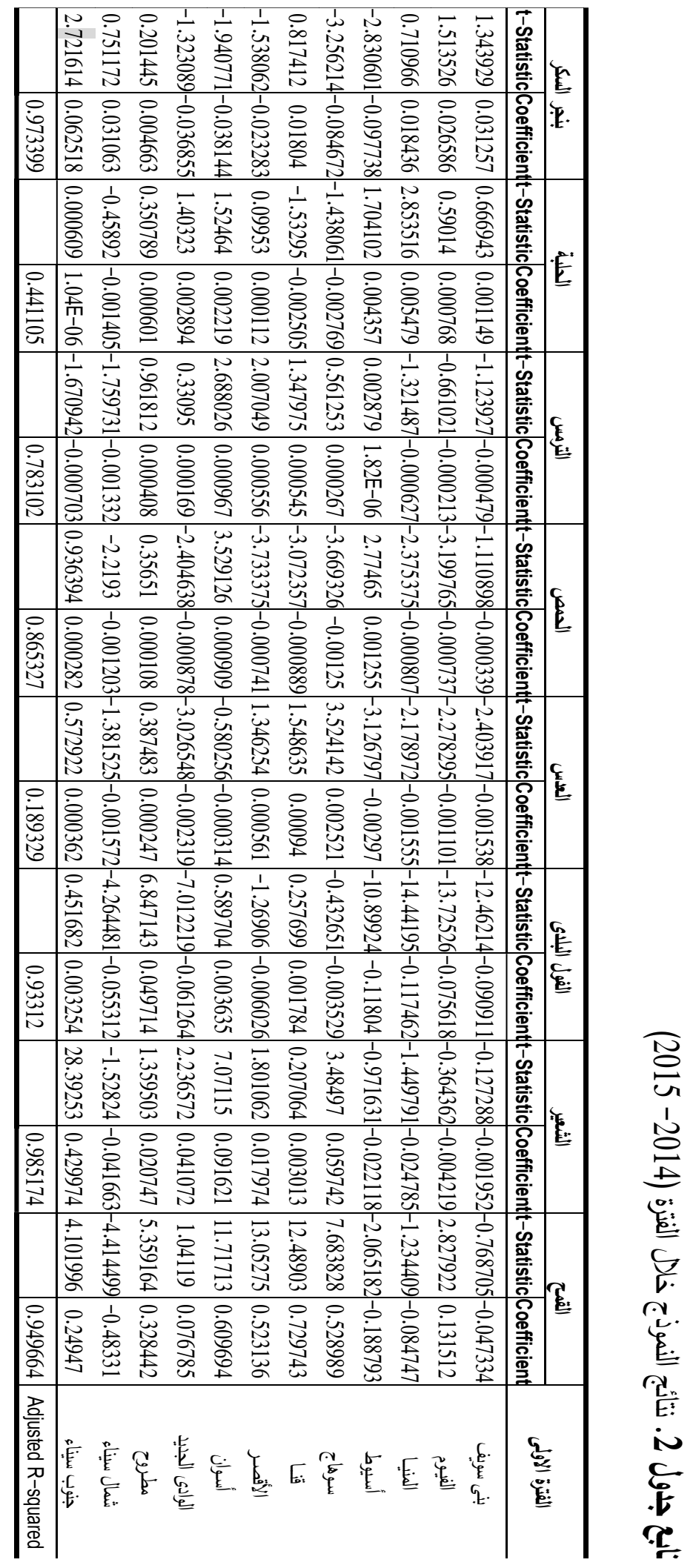




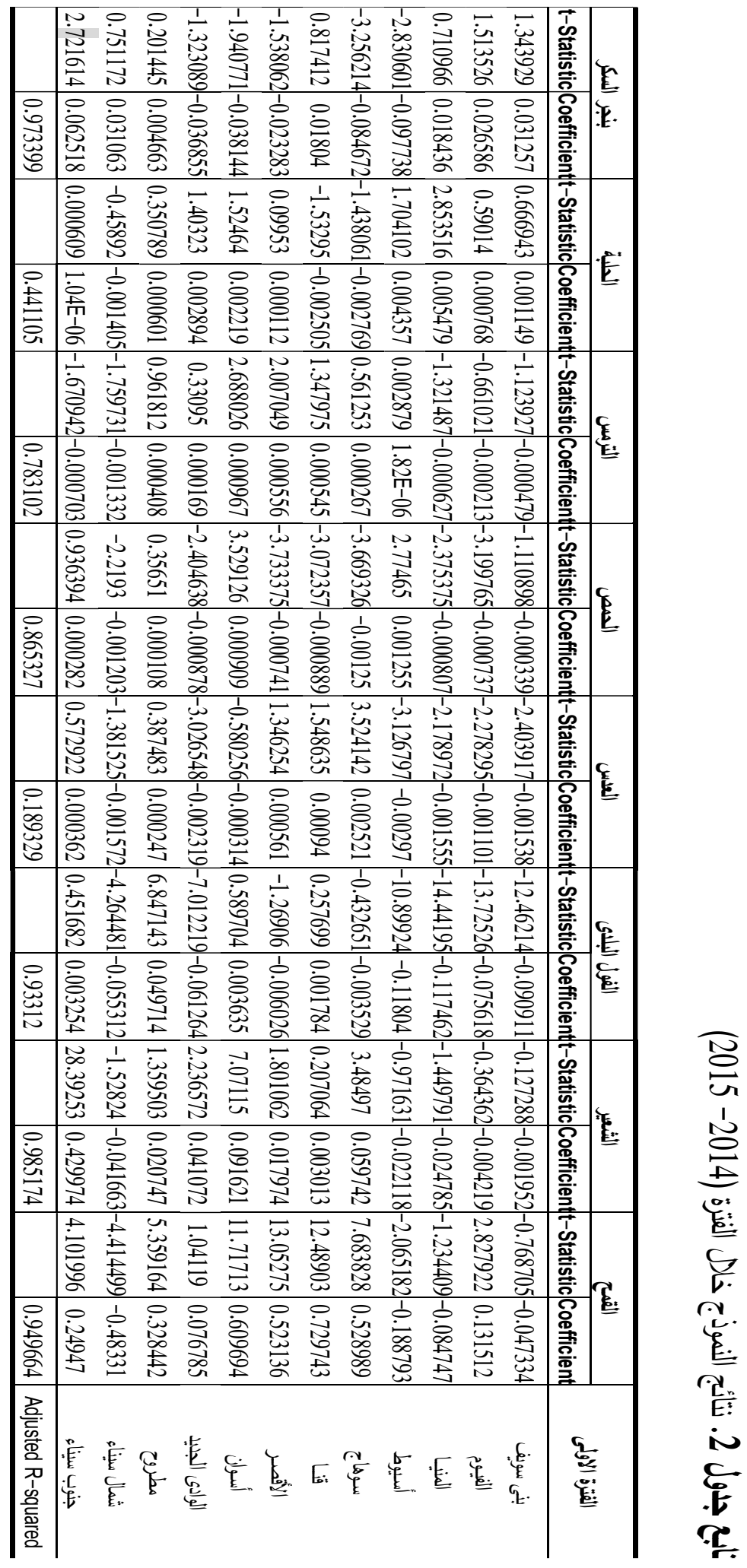




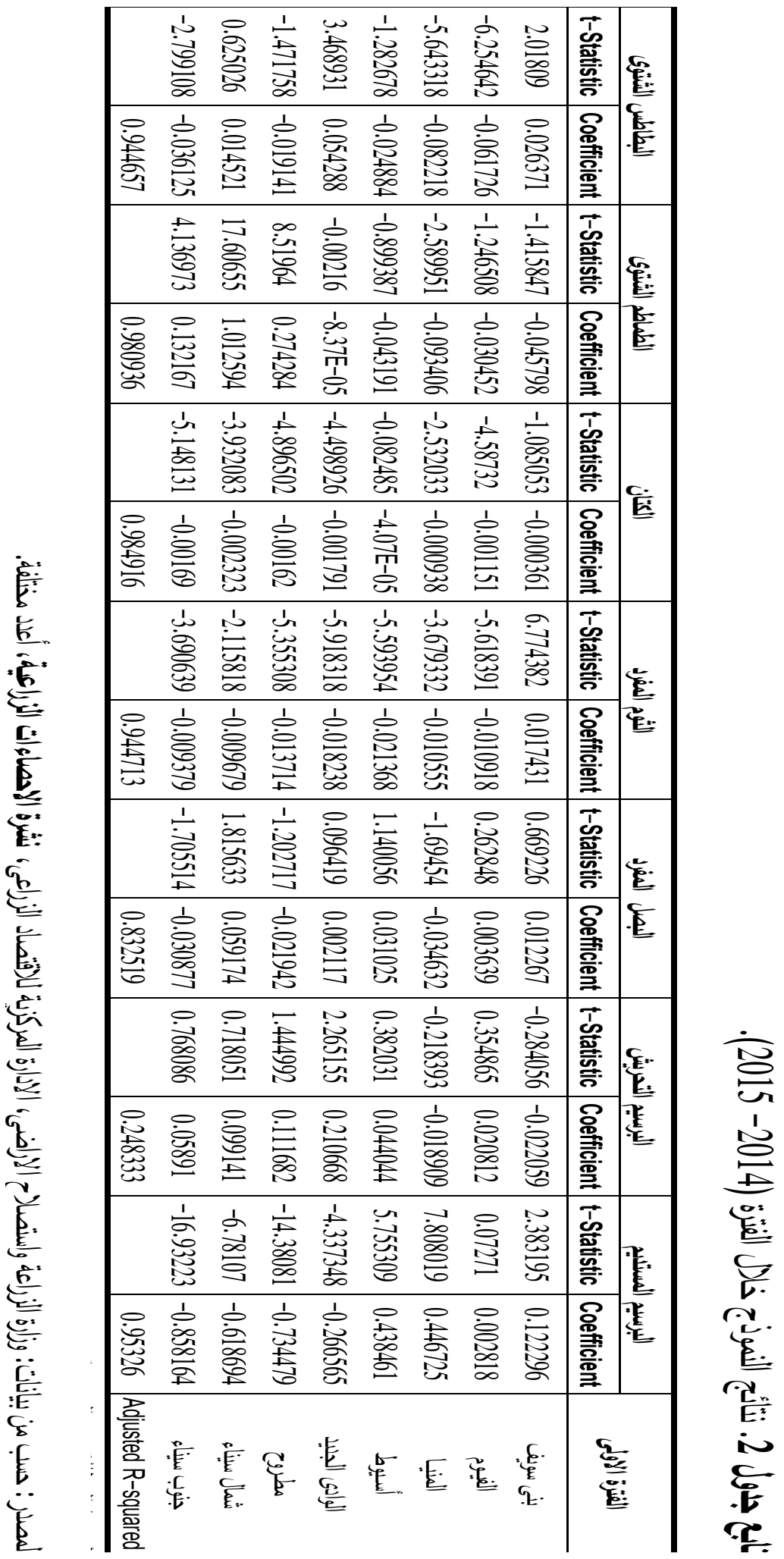




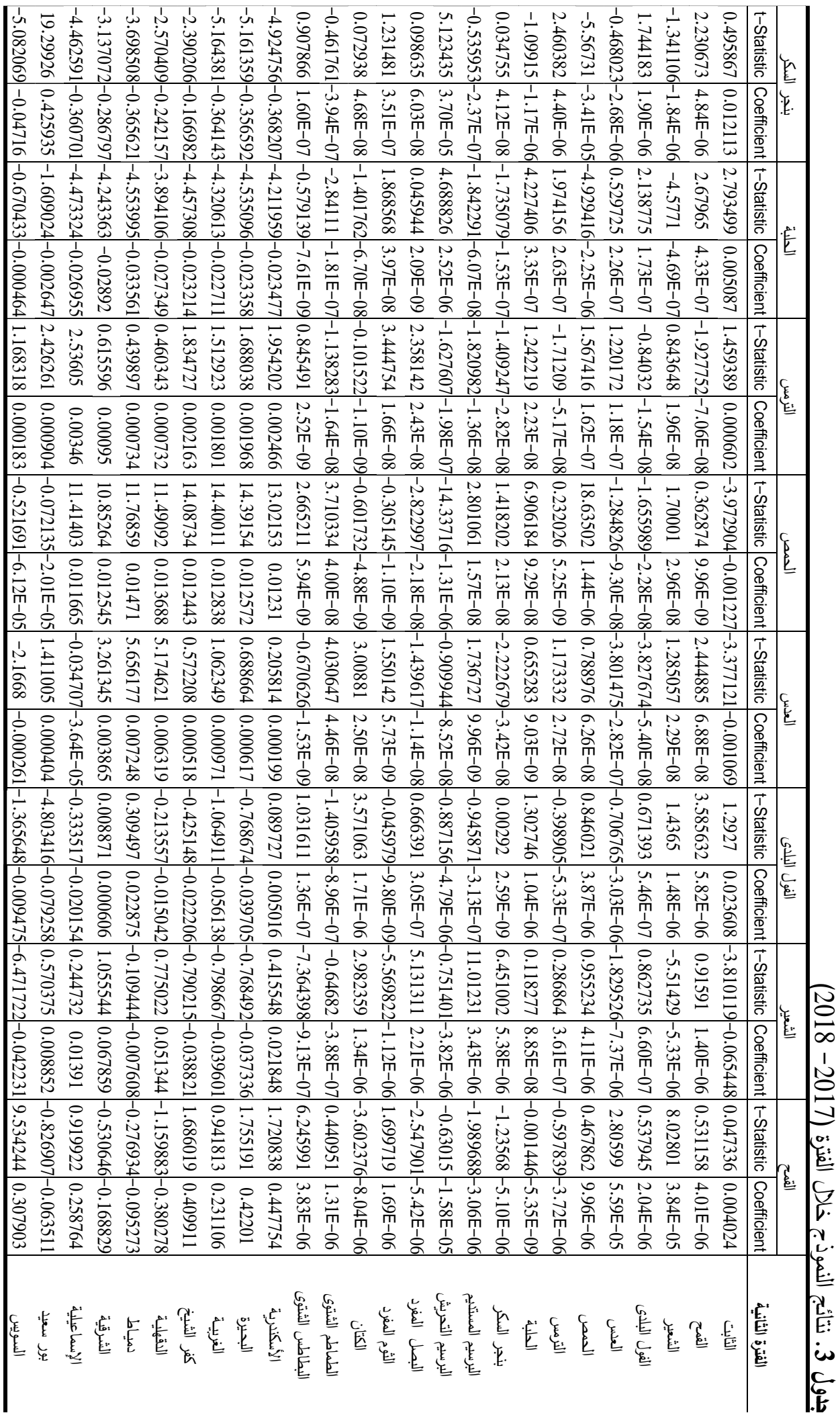




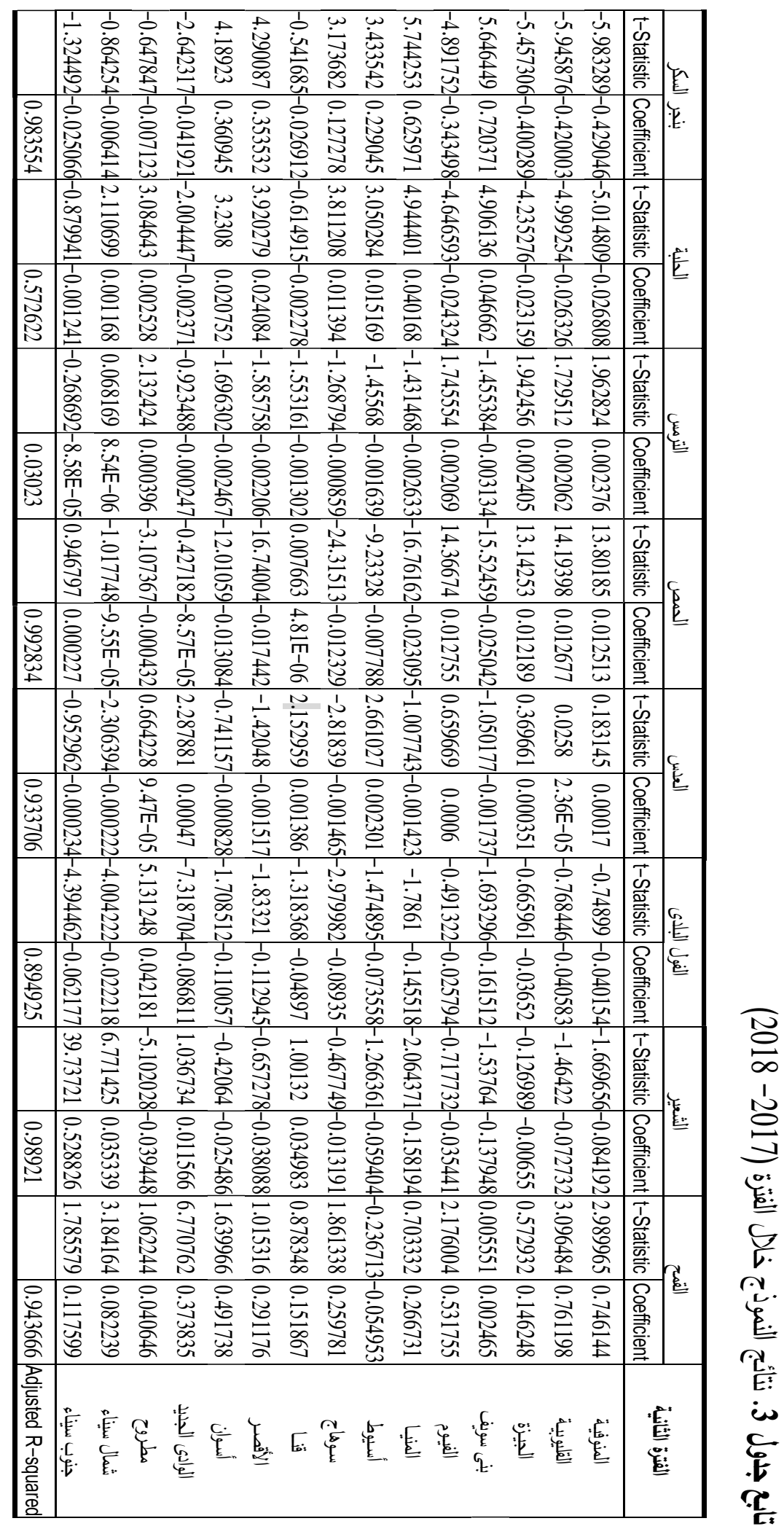




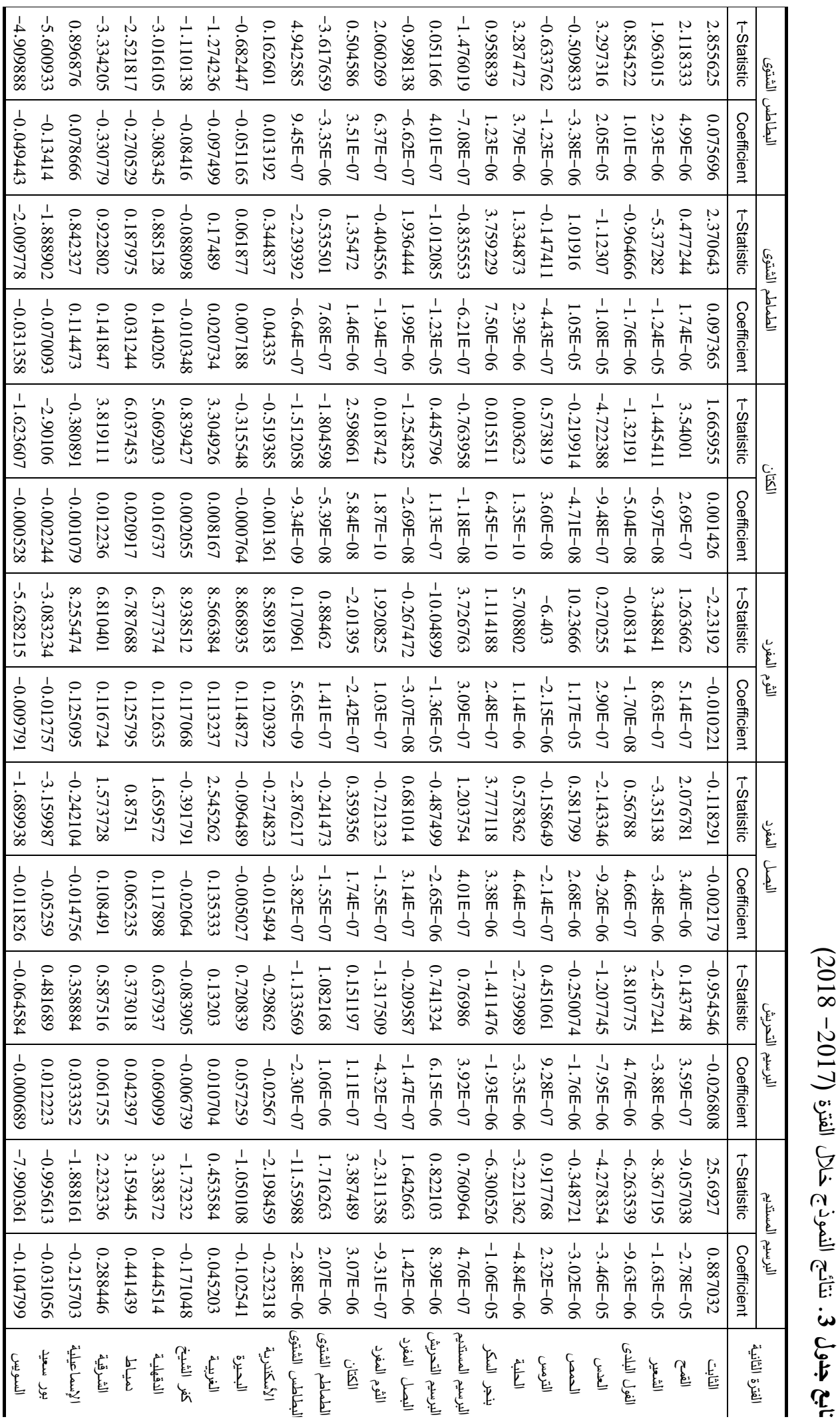




\begin{tabular}{|c|c|c|}
\hline & 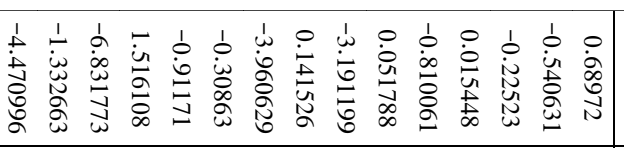 & 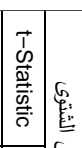 \\
\hline 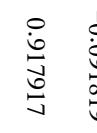 & 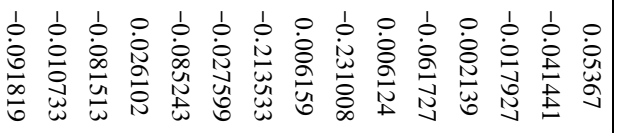 & 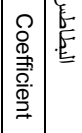 \\
\hline & 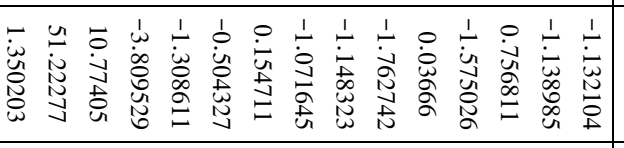 & 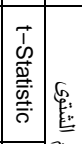 \\
\hline 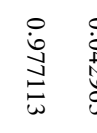 & 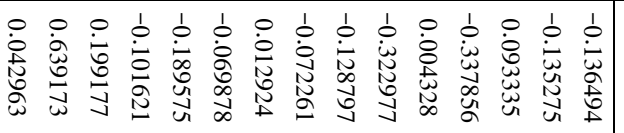 & 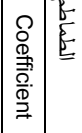 \\
\hline & 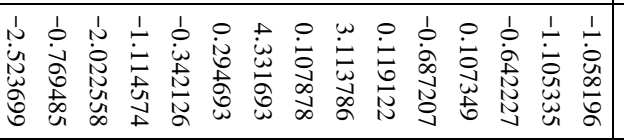 & 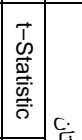 \\
\hline 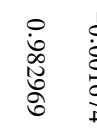 & 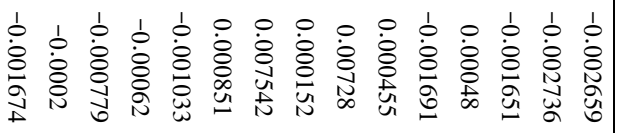 & 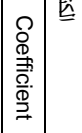 \\
\hline & 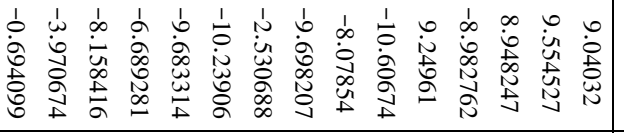 & 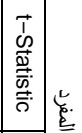 \\
\hline 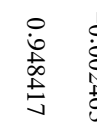 & 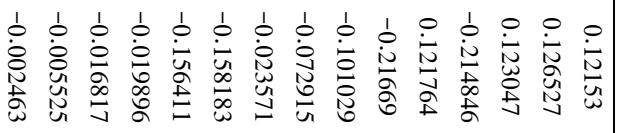 & 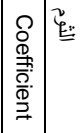 \\
\hline & 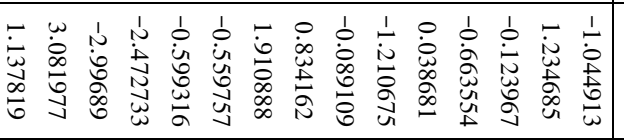 & 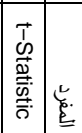 \\
\hline 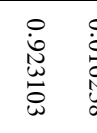 & 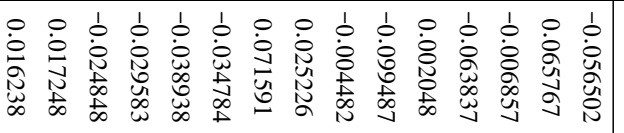 & 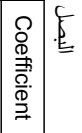 \\
\hline & 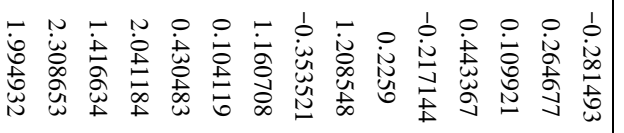 & 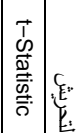 \\
\hline 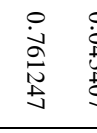 & 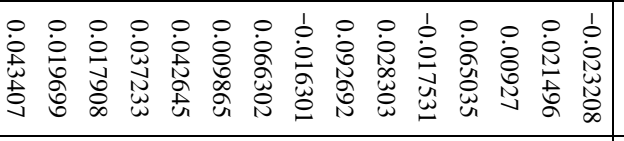 & 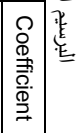 \\
\hline & 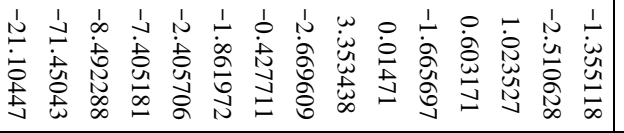 & \\
\hline 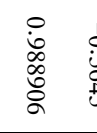 & 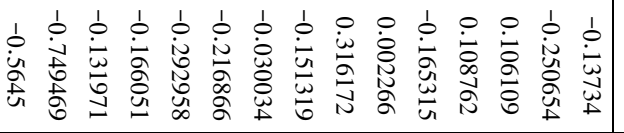 & 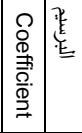 \\
\hline 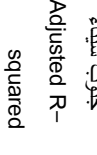 & 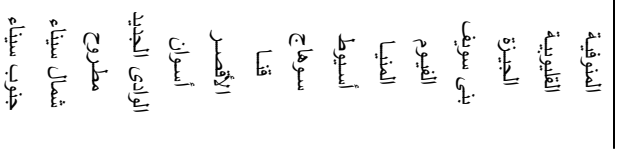 & 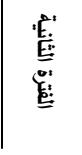 \\
\hline
\end{tabular}




\title{
A COMPARATIVE STUDY OF THE COMPETITION THE MOST IMPORTANT WINTER CROPS, USING A LINEAR APPROXIMATE MODEL
}

\author{
Moshira M. Al-Batran * \\ Sciences Commercial Dept., High Institute of Qualitative Studies, Giza, Egypt \\ *Corresponding author: moshirabatran@hotmail.com
}

Received 19 July, 2020

Accepted 5 September, 2020

\begin{abstract}
Achieving the maximum productive economic efficiency to use the available resources is considered one of the most important objectives of the agricultural economic policy, and since the agricultural area is limited, therefore the decision to choose the appropriate crop for agriculture is subject to many considerations, perhaps the most important of which is the expected revenue of these crops, as it reflects many important factors that affect decisions farming at farms, such as prices and expected production of agricultural crops. The research problem is represented in the following question: How competitive and affect the cultivated area different crops, and do changes occur from one period to another? The research aims to compare the Competitive of the most important winter crops on agricultural land during the two periods (2014-2015), (2017-2018). The most important results were as follows: It was found that there are other factors that determine the cultivated area other than the farm prices for some crops, namely wheat, barley, onions, flax, and potatoes during the period (20142015), barley, lentils, and lupine during the period (2017-2018). Low price elasticity and response was shown for chickpeas, lupine, fenugreek, tomatoes during the period (2014-2015), wheat, beans, sugar beets, persistent clover, onions, garlic, flax, tomatoes, and potatoes during the period (2017-2018). It was found that there were crops that responded more in the period (2017-2018) than the period (2014-2015), which were wheat, chickpeas, fenugreek, onions, flax, tomato and potatoes. It turns out that both chickpeas and lupine were exposed to

competition from the rest of the crops during the two periods, and that wheat, broad bean, sugar beet, and flax did not compete for them in the second period, and on the other hand, clover, onions, and garlic continued to compete with other crops. Decreased Competition in the period (2017-2018) was shown in general compared to the period (20142015). It was found that wheat and garlic were the most Interchangeability competitive, and tomatoes, broad bean, lentils and sugar beets were the most competitive crops of other crops, that lupine, fenugreek, and onions were the most competitive with other crops for the period (2014-2015). It was found that broad bean, clover, and clover Tahreesh were the most Interchangeability competitive, and barley, lentils, and potatoes were the most competitive crops of other crops, that flax, wheat, lupine, and tomato were the most competitive with other crops for the period (2017-2018). It shows the dynamics and instability of the agricultural map (with some being affected less) despite the convergence of periods. The research recommends, in order achieving maximum economic efficiency and production for the use of available resources, following: The agricultural policies applicable must be consistent with the changes that occur in the competitive of crops. Considerate the dynamics and instability of the agricultural map when setting agricultural policies. Factors other than prices must be used when determining the cultivated area of some crops, as a result of their lack of effect on some crops and their weak effect on others. Providing appropriate means (not necessarily financial support - Extension services, for example) to improve competition for some strategic crops.
\end{abstract}

